\title{
Aproximación al estudio del objeto del derecho administrativo
}

\author{
Ronald Pacheco-ReYes ${ }^{1}$
}

\section{RESUMEN}

Con fundamento en la revisión de las teorías que alrededor del objeto del derecho administrativo se han planteado a lo largo de los años, y teniendo en cuenta el medio científico, social, económico y político en el que las mismas se han presentado, este escrito propone una perspectiva contextual para abordar el estudio del objeto de esta disciplina. Esta perspectiva permite entender tales teorías, no como un abanico de teorías acertadas y/o erradas, sino como el reflejo de cada momento histórico particular. Con esta premisa surge la necesidad de la reflexión sobre el entorno actual del derecho administrativo y el replanteamiento de sus herramientas clásicas de estudio.

Palabras clave: Derecho administrativo, Objeto del derecho administrativo, Teorías sobre el objeto del derecho administrativo, Administración pública, Cosmovisión, Historia, Modernidad, Posmodernidad, Complejidad, Sistemas, Regulación.

1 Abogado, magíster en Derecho con énfasis en Derecho Administrativo y especialista en Derecho Administrativo de la Universidad Externado de Colombia, Bogotá, Colombia. Asesor jurídico del Ministerio de Hacienda y Crédito Público, Bogotá, Colombia. Correoe: ronaldpachecoreyes@hotmail.com Fecha de recepción: 10 de enero de 2017. Fecha de modificación: 15 de marzo de 2017. Fecha de aceptación: 30 de mayo de 2017. Para citar el artículo: PACHECO-ReYES, R. "Aproximación al estudio del objeto del derecho administrativo", Revista digital de Derecho Administrativo, n. ${ }^{\circ} 18$, segundo semestre, Universidad Externado de Colombia, 2017, pp. 23-63. DOI: https://doi.org/10.18601/21452946.n18.04 


\title{
An Approach to the Study of the Subject of Administrative Law
}

\begin{abstract}
Based on the revision of theories that have arisen around the existence of the administrative law over the years and, taking into account the scientific, social, economic and political environment in which they have been presented, this paper proposes a contextual perspective to approach the study of the subject of this discipline. This perspective allows one to understand such theories not as a range of right and/or wrong theories, but as a reflection of each particular historical moment. With this premise arises the need for reflection on the current environment of Administrative Law and the rethinking of the classical tools used for its study.
\end{abstract}

Keywords: Administrative Law, Object of Administrative Law, Public Administration, Cosmovision, History, Modernity, Postmodernity, Complexity, Systems, Regulation.

\section{INTRODUCCIÓN}

El objeto del derecho administrativo ha sido un tema ampliamente estudiado pero poco acordado; a su alrededor se han perfilado las más variadas posiciones, y el hecho de que después de tantos años actualmente se siga estudiando refleja la complejidad de tal empresa ${ }^{2}$. Los estudiosos de la materia han propuesto diversas teorías para intentar explicar el objeto del derecho administrativo, y dentro de las posturas más conocidas están las denominadas tesis subjetivas, las objetivas y las que combinan algunas o todas las anteriores. Desde luego, también hay algunos pensadores ${ }^{3}$ que niegan la utilidad práctica del estudio de este asunto, lo cual es una posición respetable, sin embargo, con poco sustento práctico, por lo menos para el caso colombiano. Basta revisar la historia de los debates judiciales ${ }^{4}$ que se han presentado en nuestro ordenamiento jurídico a propósito de la definición del objeto de conocimiento de la jurisdicción

2 Oriol Mir Puigpelat, "El concepto de derecho administrativo desde una perspectiva lingüística y constitucional", Revista de Administración Pública, n. ${ }^{\circ}$ 162, septiembre-diciembre, Madrid: CEPC, 2003, p. 47.

3 Por ejemplo, "Santamaría Pastor cuando afirma que la búsqueda teórica del concepto de Derecho administrativo carece de toda utilidad práctica": ibíd.

4 Ver, entre otras, las siguientes sentencias de la Sección Tercera del Consejo de Estado: del 20 de agosto de 1998, rad. 14202, y del 21 de noviembre de 2013, rad. 46027. En esta última se realiza un estudio sobre la historia de la legislación relacionada con el objeto de la jurisdicción contencioso administrativa. 
contencioso administrativa para ver la importancia del tema. Por su parte, el legislador, partiendo de la Ley 130 de 1913 y pasando por el Decreto 01 de 1984, con sus modificaciones, y terminando con el actual Código de Procedimiento Administrativo y de lo Contencioso Administrativo (Ley 1437 de 2011 $\mathrm{y}$, por sus siglas, CPACA), no ha hecho más que reflejar la importancia que en determinado momento les ha dado a las mencionadas tesis que han estudiado el objeto del derecho administrativo.

Pero, como se dijo, a pesar de ser un tema ampliamente debatido, incluso hoy, no se tiene total claridad sobre el objeto del derecho administrativo. Para la muestra puede verse que, a pesar de la intención abarcadora que se evidencia en el artículo 104 CPACA -al combinar varias tesis o criterios para definir el objeto del derecho administrativo y, por ende, la competencia de la jurisdicción contencioso administrativa-, siguen suscitándose dudas sustanciales en relación con la materia. Se observa que el citado artículo señala que "[1]a Jurisdicción de lo Contencioso Administrativo está instituida para conocer, además de lo dispuesto en la Constitución Política y en leyes especiales, de las controversias y litigios originados en actos, contratos, hechos, omisiones y operaciones, sujetos al derecho administrativo, en los que estén involucradas las entidades públicas, o los particulares cuando ejerzan función administrativa" (cursiva fuera del texto original); sin embargo, no hay ningún parámetro normativo o jurisprudencial claro que defina qué es el derecho administrativo y, por tanto, tampoco forma de determinar cuándo se está o no en frente de esta rama del derecho. Esta incertidumbre aumenta cuando se comprueba que en dicho sector se acude al uso de figuras tradicionales del derecho común, aunado a la constatación de situaciones que tornan borrosa la frontera -si es que aún existe- entre el derecho público y el derecho privado ${ }^{5}$. No se trata, entonces, de un tema irrelevante para el sector jurídico administrativo y para quienes se relacionan con este. Incluso, el Consejo de Estado, estudiando este asunto, señaló que "uno de los grandes problemas que ofrece el derecho administrativo moderno radica, precisamente, en la dificultad de concretar su definición, pues las nociones clásicas no responden a la versatilidad, a los cambios y a la naturaleza indiferenciada que el derecho en general ha adquirido en ciertos lugares, espacios y contextos de la actualidad de la administración"6.

5 Con esta frontera venían debates entre privatistas y publicistas: "Las luchas internas entre los privatistas y los publicistas deben su ambigüedad al hecho de que los primeros, en tanto que guardianes del derecho de propiedad y del respeto a la libertad de los contratos, se hacen defensores de la autonomía del derecho y de los juristas contra todas las intrusiones de la política y de los grupos de presión económicos y sociales y, en particular, contra el desarrollo del derecho administrativo, contra las reformas penales y contra todas las innovaciones en materia social, comercial o en la legislación del trabajo": Pierre Bourdieu y Gunther Teubner. La fuerza del derecho, Estudio preliminar y traducción de Carlos Morales de Setién Ravina, Bogotá: Siglo del Hombre Editores y Ediciones Uniandes, 2000, p. 217. 
En el ámbito español, estos debates no son pocos. Frente a este aspecto, Oriol Mir Puigpelat ${ }^{7}$ expone varias razones que reafirman la importancia del estudio del objeto del derecho administrativo, y entre ellas destaca que definir este punto equivale a identificar el límite $y$, por ende, la diferencia con otras especialidades jurídicas; así mismo, resalta consecuencias prácticas a nivel acádemico, por ejemplo, para determinar el contenido de una asignatura, $y_{\text {, }}$ para efectos jurídico positivos, describe múltiples casos en los cuales el derecho español remite al concepto jurídico "derecho administrativo"; es decir, hay que saber qué es el derecho administrativo para poder comprender y aplicar cabalmente la norma que lo menciona; a propósito, razones que también aplican para el ordenamiento jurídico colombiano.

Los anteriores párrafos pretenden destacar dos fenómenos, por un lado, la importancia del estudio del objeto del derecho administrativo, por otro, la dificultad para encontrar el objeto de conocimiento definitivo de esta disciplina. De este último punto se ocupa el presente escrito, aclarando que no se aborda, o por lo menos, no directamente, el objeto del derecho administrativo, sino los estudios que se han realizado sobre el mismo. Para decirlo con una metáfora, no se busca cazar al conejo, sino que se intenta entender cómo los cazadores han intentado cazarlo. Esta actitud, desde el punto de vista metodológico, se conoce en la sociología con el nombre de observación de segundo orden, que pone al investigador "en el nivel de la observación de los observadores"8.

A partir de esta forma de observación se planteará la siguiente hipótesis: a la fecha no ha sido posible identificar, de una vez por todas, el objeto del derecho administrativo porque las teorías propuestas al respecto no son el resultado de descubrimientos de una realidad que, de manera definitiva, deba regir para siempre ${ }^{9}$; las tesis sobre el objeto de esta rama del derecho no son el descubrimiento -utilizando palabras de Ospina Garzón- de la partícula

7 Oriol Mir PuigPelat, "El concepto de derecho administrativo desde una perspectiva lingüística y constitucional", cit., pp. 49 ss.

8 Niklas Luhmann, El derecho de la sociedad, México: Herder, 2009, p. 126.

9 La continua búsqueda del objeto del derecho administrativo hace necesario dar una mirada a la continua búsqueda de la verdad en el pensamiento científico moderno. "En la Modernidad se concibió el conocimiento como el reflejo interno en el sujeto del mundo externo, al que se supone objetivo e independiente": Denise Najmanovich, Mirar con nuevos ojos nuevos paradigmas en la ciencia y pensamiento complejo, Biblos, 2008 pp. 15 ss. Sin embargo, esta concepción del conocimiento ha comenzado a cambiar en el siglo XX, dando paso al conocimiento entendido como un fenómeno en el que se relacionan el sujeto y el objeto como un todo inseparable. Esta idea, de una forma muy resumida, es expresada con la siguiente reflexión de dos famosos pensadores chilenos: "Todo lo dicho es dicho por alguien": Humberto Maturana y Francisco Varela. El árbol del conocimiento, Buenos Aires: Lumen y Editorial Universitaria, 2013, p. 14. Los programas que impulsan esta nueva forma de entender el conocimiento son conocidos de diversas formas, entre estas, la fenomenología (particularmente la de Maurice Merleau-Ponty), la teoría general de sistemas, las ciencias de la complejidad, las ciencias cognitivas, entre otras. 
de $\operatorname{Dios}^{10}$, sino que son una construcción sujeta a evolución que resulta de la observación de las premisas teóricas y realidades prácticas existentes en la época en que cada teoría surge. Dicho en términos sistémicos: el derecho administrativo es un subsistema - del sistema jurídico- que evoluciona continuamente y se adapta y retroalimenta con su entorno ${ }^{11}$. Y, ¿qué aporta esta hipótesis? En síntesis, una perspectiva de investigación que contribuye a ver conexiones y comportamientos valiosos que con un método exclusivamente jurídico difícilmente saldrían a flote.

Tal forma de abordar la materia permite observar las distintas tesis que se han elaborado para describir el objeto del derecho administrativo no como construcciones teóricas que compiten entre sí por ser la acertada ${ }^{12}$, sino, por el contrario, aportando una perspectiva en la que las distintas explicaciones sobre el objeto del derecho administrativo son vistas como el resultado de un continuo histórico fruto de la evolución. Esta perspectiva se pondrá a prueba, como se verá más adelante, con un análisis del entorno científico, social, político y económico que rodea al derecho administrativo actual.

La hipótesis expuesta se sustentará haciendo una breve exposición de las más conocidas (I) teorías, posturas o criterios que se han formulado para explicar el objeto del derecho administrativo. Posteriormente, se realizará una revisión histórica de las principales cosmovisiones de la sociedad que han acompañado, desde su aparición hasta nuestros días, al derecho administrativo para tratar de comprender la (II) configuración y evolución del derecho administrativo en cada periodo histórico. Con fundamento en la metodología utilizada en los puntos anteriores, se presentará una descripción de lo que se ha denominado un nuevo orden social y, por consiguiente, (III) los efectos que se están generando en el derecho administrativo de nuestros días.

Antes de comenzar con el desarrollo del plan mencionado, es necesario realizar la siguiente precisión metodológica. Normalmente, junto con el estudio del objeto del derecho administrativo, se estudia el origen o génesis $-\mathrm{y}$

10 Ver Andrés Fernando Ospina Garzón, "Separación de poderes y derecho administrativo: en la búsqueda de la partícula de Dios", en Andrés Fernando Ospina Garzón y Alberto Montaña Plata (eds.), La constitucionalización del derecho administrativo, XV Jornadas Internacionales de Derecho Administrativo, Bogotá: Universidad Externado de Colombia, 2014, pp. 117 ss.

11 Esta idea la expresa Schmidt-Aßmann afirmando que "[s]i se pone de manifiesto que una determinada teoría general no conduce a resultados razonables o adecuados, no ya sólo en un concreto ámbito del Derecho administrativo especial, sino en todo un sector intermedio, tendremos entonces un indicio de que habrá que cuestionarla y someterla a revisión. Y a la inversa: las propuestas de revisión emanadas desde la Parte especial habrán de ponerse a prueba en la Parte general": EBeRHARD SCHMidT-ASSMANn, La teoría general del derecho administrativo como sistema, Madrid: Marcial Pons, 2003, p. 15.

12 "Así, las teorías objetivo-funcionales y las orgánico-subjetivas se han venido relevando a lo largo del tiempo, en una especie de competición sin ganador definitivo": OrIOL MIR PuigPelat, "El concepto de derecho administrativo desde una perspectiva lingüística y constitucional", cit. p. 63. 
de paso el lugar de nacimiento- de esta disciplina jurídica. En ese sentido, son conocidos los debates entre pensadores que sitúan la génesis del derecho administrativo en Francia, otros en Inglaterra y algunos en Roma ${ }^{13}$. Incluso, se han diseñado "modelos tipo" para explicar este asunto ${ }^{14}$. Aunque -se reconoceexiste una interconexión necesaria entre el momento y el lugar de aparición del objeto del derecho administrativo -la cual necesariamente se verá reflejada en el desarrollo de este escrito--, en esta exposición se entenderá que existe derecho administrativo desde el momento en que el derecho lo reconoce; es decir, cuando un sistema jurídico realiza referencias al concepto jurídico "derecho administrativo" existirá tal objeto ${ }^{15}$. Con esto no se quiere negar la importancia de los estudios que buscan la génesis del derecho administrativo en épocas remotas; no obstante, en esta oportunidad serán solo eso, es decir, búsqueda de antecedentes de la materia, mas no la materia misma. Para decirlo en una frase: seguramente antes de la Revolución Francesa se administraba, pero no existía el derecho administrativo porque, entre otras cosas, este no era "jurídicamente nombrado"16.

De acuerdo con esta precisión, se entenderá -con Sabino Cassese- que la "expresión droit administratif aparece en Francia a finales del siglo XVIII y se propaga bajo el primer Imperio ${ }_{i}[\ldots]$ El Derecho Administrativo nace en Francia por efecto de la Revolución francesa y del Imperio napoleónico, que abaten no sólo las instituciones políticas del Antiguo Régimen sino también las administrativas ${ }^{\prime \prime 17}$. A partir de este momento, con la positivización del derecho administrativo, junto con el rol intenso del Conseil d'État en la materia y los valiosos esfuerzos de inventario de profesores que, a su vez, eran juristas de profesión ${ }^{18}$, se fundaron los cimientos de esta disciplina que a día de hoy no deja de evolucionar.

13 Ver Nicolás Cabezas y Daniel Mayorga, "La génesis del derecho administrativo: fenómeno y derecho de la administración romana", Revista digital de Derecho Administrativo, n. ${ }^{\circ} 16$, segundo semestre, Universidad Externado de Colombia, 2016, pp. 297-335. DOI: http:// dx.doi.org/10.18601/21452946.n16.14

14 SABINo CASSESE, Derecho administrativo: bistoria y futuro, Madrid: Global Law Press, Editorial Derecho Global, 2010, pp. 24 ss.

15 Esta metodología tiene su fundamento en la teoría de sistemas de Luhmann y Teubner. Este último sostiene que el "derecho es una red comunicativa que produce comunicaciones jurídicas": GUNTHER TEUBNER, El derecho como sistema autopoiético de la sociedad global, Bogotá: Universidad Externado de Colombia, 2005, p. 41. Por su parte Luhmann sostiene que "las comunicaciones jurídicas tienen, siempre, como operaciones del sistema del derecho una doble función: ser factores de producción y ser conservadores de las estructuras. Estas comunicaciones establecen condiciones de enlace para operaciones subsiguientes": NIKLAS LUHMANN, El derecho de la sociedad, cit., p. 32.

16 Luciano Parejo A., El concepto del derecho administrativo, Bogotá: Universidad Externado de Colombia, 2009, p. 115

17 SABINO CASSESE, Derecho administrativo: bistoria y futuro, cit., p. 32

18 SABINO CASSESE, Derecho administrativo: bistoria y futuro, cit., pp. 35 y 36. 
En consecuencia, con esta identificación temporal y espacial surge entonces la necesidad de precisar cuáles son las diferentes tesis ${ }^{19}$ que se han propuesto para justificar al derecho administrativo, reiterando que el punto de partida será la Francia antes, durante y después de la Revolución, eso sí, sin perjuicio de las referencias que por cuestiones de contraste metodológico se puedan hacer a otros lugares y épocas, especialmente, ejemplos del derecho colombiano.

\section{PRINCIPALES TEORÍAS RELACIONADAS CON EL OBJETO DE CONOCIMIENTO DEL DERECHO ADMINISTRATIVO}

¿Qué es el derecho administrativo?, ¿cuál es su objeto?, ¿por qué es diferente del derecho común?, entre otras, son las principales preguntas que han inspirado diversas respuestas. Unas respuestas se han presentado haciendo énfasis en la presencia de un sujeto especial, otras destacando que lo importante es que existe una función particular que cumple el Estado, y otras surgen como mixturas de los argumentos anteriores.

A continuación, para efectos metodológicos, será necesario exponer estos entendimientos o criterios de identificación del objeto del derecho administrativo de la manera más plana o neutra posible, dejando la justificación y posibles explicaciones de cada teoría para los apartes siguientes a este capítulo.

\subsection{TeOrías SUbJetivas}

En las versiones iniciales ${ }^{20}$ de estas teorías habrá derecho administrativo en aquellos casos en los que se identifique la presencia de la rama ejecutiva del poder público. El criterio clave para determinar si debe o no estar presente este derecho especial es identificar la presencia de un sujeto -también-especial que, como lo destaca Montaña, en algunos casos ha sido identificado con el concepto de administración pública ${ }^{21}$. A grandes rasgos, puede decirse que el ejercicio de verificación de existencia o no de derecho administrativo era relativamente sencillo, pues si había una manifestación de la administración pública, entendida esta como estructura propia de la rama ejecutiva, procedía este régimen jurídico especial y no el derecho común.

19 Algunos autores identifican que en el devenir de las teorías sobre el objeto del derecho administrativo se presenta un movimiento pendular entre unas y otras, sin embargo, para efectos metodológicos en esta exposición se hace énfasis en cada teoría original y no en la vuelta del péndulo a las mismas. Ver Oriol Mir PuigPelat, "El concepto de derecho administrativo desde una perspectiva lingüística y constitucional", cit., p. 63.

20 Jaime Orlando Santofimio Gamboa, Tratado de derecho administrativo, t. I, Bogotá: Universidad Externado de Colombia, 2007, p. 49.

21 Alberto Montaña Plata, Fundamentos de derecho administrativo, Bogotá: Universidad Externado de Colombia, 2010, p. 41. 
Desde luego, estas teorías subjetivas han tenido diferentes versiones, tantas, que en algunos casos, o bien no es sencillo ubicarlas metodológicamente en alguna de las clases de teorías que puedan presentarse, o bien no parece existir una diferencia significativa entre las diversas versiones. Sin embargo, pueden encontrarse trabajos de clasificación que son útiles para tener un conocimiento más detallado; en este sentido, Santofimio ha descrito como variaciones de las posturas subjetivas o, como las denomina en su obra, "criterios orgánicos", los siguientes: el orgánico-funcional, el orgánico-institucional y el orgánico personalista. En el primer caso, "el objeto del derecho administrativo consiste en todo aquello que le es propio y característico al ejecutivo" ${ }^{122}$; en la segunda versión, el objeto del derecho administrativo implica la presencia "de una institución administrativa, esto es, un cuerpo de sujetos u órganos conocidos y adjetivados como administrativos ${ }^{123}$; y, en la última variación, "el derecho administrativo será el derecho de la administración como persona jurídica: un derecho público, estatutario, en cuanto sólo referido y propio de la administración pública generalmente considerada"24.

Como se mencionó en la introducción de este escrito, estas construcciones doctrinales han tenido, y continúan teniendo, consecuencias en la práctica y en el sistema jurídico, y para efectos ejemplificadores puede verse que en los inicios de nuestra legislación contencioso administrativa se hizo evidente la inclinación por este tipo de teorías. Así, el artículo 1. ㅇ de la Ley 130 de 1913, "Sobre la jurisdicción de lo contencioso administrativo", señalaba:

La jurisdicción contencioso administrativa tiene por objeto la revisión de los actos de las corporaciones o empleados administrativos en el ejercicio de sus funciones, o con pretexto de ejercerlas, a petición del Ministerio Público, de los ciudadanos en general, o de las personas que se crean vulneradas en sus derechos, en los casos y dentro de los límites señalados en la presente Ley (resaltado fuera del texto original).

Es decir, el control judicial propio del régimen jurídico administrativo se activaría siempre y cuando existieran manifestaciones de corporaciones o empleados administrativos, en últimas, de sujetos pertenecientes a la administración pública.

Las críticas que han tenido estas tesis subjetivas han tenido su fundamento en situaciones presentadas en la práctica, por ejemplo, hipótesis de ejercicio de funciones en apariencia administrativas en ramas del poder público distintas de la ejecutiva ${ }^{25}$. Cuestiones problemáticas que, como era de esperarse, encontraron respuesta en la doctrina y consecuentemente en el derecho positivo. 


\subsection{TeOrías Objetivas}

Estas teorías sostienen que habrá derecho administrativo cuando se identifique un objeto especial: la administración pública vista como verbo, en otras palabras, entendida ya no como un conjunto de órganos adscritos a un sujeto especial, sino como un hacer traducido en el "administrar público"; por consiguiente, para encontrar el objeto de este derecho especial, lo esencial es identificar el ejercicio de función administrativa ${ }^{26}$. Igual que ocurrió con las tesis subjetivas, estas posturas o criterios para identificar el derecho administrativo también tuvieron diversificaciones, principalmente construidas para darle significado al concepto de función administrativa, en ese sentido, surgieron la tesis de las prerrogativas públicas y la de los servicios públicos.

Para la primera de las tesis, explica Montaña, "la justificación del régimen administrativo guarda una estrecha relación con la verificación del necesario ejercicio de prerrogativas públicas por parte de algunos sujetos de derecho -en su origen públicos-; es entonces la capacidad que tienen de imponerse legítimamente algunos sujetos frente a otros lo que justifica la procedencia de un régimen jurídico administrativo ${ }^{\prime 27}$. Puede verse, entonces, que el carácter definitorio del objeto del derecho administrativo era el ejercicio del poder público. Para la segunda de las tesis, el concepto de servicio público, al comprender en la práctica la manifestación de una técnica prestacional dirigida a satisfacer el interés general, justifica la existencia de un derecho especial porque este se encarga de servir de instrumento para alcanzar los fines de dicho concepto ${ }^{28}$.

Estas dos tesis emergieron en la denominada edad de oro del derecho administrativo, en la que esta disciplina alcanzó un desarrollo sustancial, pero también, como las anteriores posturas -subjetivas-, fueron objeto de críticas. Esencialmente, la aparición de sujetos particulares prestando servicios públicos comenzó a desmoronar el edificio de las tesis objetivas, y comenzó a ser necesario nuevamente el estudio de la materia.

\subsection{TEORÍAS MIXTAS}

En estas posturas o criterios doctrinales se concluye que el objeto del derecho administrativo lo constituye la administración pública entendida como órgano y como función, es decir, se intenta combinar las tesis subjetivas y objetivas con el propósito de superar las debilidades de las mismas.

Carlos Covilla Martínez, "Identificación de la función administrativa internacional como criterio para definir la administración pública desde una perspectiva funcional", Revista digital de Derecho Administrativo, n. ${ }^{\circ}$ 12, Bogotá: Universidad Externado de Colombia, 2014, p. 173. 
Autores como Rivero y Vedel, en Francia, o como S. Martín-Retortillo, Martín Mateo y J. A. García-Trevijano, en España, se han negado a definir el Derecho administrativo sobre un único criterio, objetivo o subjetivo, y se han mostrado partidarios de concepciones eclécticas, afirmando expresamente la necesidad de combinar criterios objetivos y subjetivos para aprehenderlo en su totalidad ${ }^{29}$.

Estas tesis mixtas también parecen haber incidido en el ordenamiento jurídico positivo $\mathrm{y}$, para el caso colombiano, puede hacerse seguimiento a lo sucedido con el Código Contencioso Administrativo (Decreto 01 de 1984) y sus distintas modificaciones ${ }^{30}$ hasta la aparición del Código ${ }^{31}$ que reemplazó al anterior. No se abandona - por no ser físicamente posible- la alusión a la existencia de órganos y entran en escena los conceptos de funciones públicas o función administrativa, ejercidas ya no necesariamente por entidades típicamente administrativas, sino por entidades públicas, algunas sociedades estatales, e igualmente por particulares, y además se acudió a la enumeración de hipótesis concretas con el propósito de abarcar todas las posibilidades de interés del legislador ${ }^{32}$.

No obstante, como se enunció en la introducción de este trabajo, estas construcciones teóricas no han generado tranquilidad en el sector porque siempre surgen inquietudes prácticas y doctrinales que se presentan al momento de determinar la procedencia o no del derecho administrativo. Parece que no ha sido suficiente combinar los criterios históricos descritos debido a que la realidad comienza a mostrar fenómenos que no encajan en los conceptos fundantes de ambas tesis. Cada vez más aparecen funciones administrativas ejercidas, no solo por otras ramas, sino también por otros órganos ubicados fuera de estas, igualmente por particulares, e incluso por organismos internacionales ${ }^{33}$; a su vez, el Estado ha tomado, en algunos momentos, iniciativas típicamente económicas que extrañan a los conceptos clásicos de actividad administrativa.

29 Oriol Mir Puigpelat, "El concepto de derecho administrativo desde una perspectiva lingüística y constitucional", cit., p. 67.

30 Decreto 2304 de 1989, Ley 446 de 1998 y Ley 1107 de 2006.

31 Código de Procedimiento Administrativo y de lo Contencioso Administrativo, expedido con la Ley 1437 de 2011.

32 Art. 104 de la Ley 1437 de 2011.

33 Juan Carlos Covilla aborda este fenómeno en "Identificación de la función administrativa internacional como criterio para definir la administración pública desde una perspectiva funcional", cit. 


\section{CONFIGURACIÓN Y EVOLUCIÓN DEL DERECHO ADMINISTRATIVO}

Una verificación de las teorías expuestas en el punto anterior permite sostener dos afirmaciones. La primera es que siempre se ha partido -independientemente de cómo se le denomine- de un lugar común: la administración pública, solo que algunos doctrinantes la han entendido como un sujeto (órgano que administra) y otros como una función especial (dentro del abanico de las funciones estatales) ${ }^{34}$. La segunda afirmación es que los errores o falencias que los autores de las teorías subjetivas y objetivas se enrostran mutuamente obedecen a la misma causa: el análisis reduccionista ${ }^{35}$, o bien porque solo se estudia un componente de la realidad sin tener en cuenta otros componentes con los que aquel se relaciona, o bien porque se juzga a determinada postura de una manera descontextualizada; para decirlo con palabras coloquiales, las falencias que se imputan mutuamente estas teorías obedecen a que se observa solo una cara de la misma moneda, o a no intentar ponerse en los zapatos del otro. Ahora, también debe destacarse que algunos estudiosos han sostenido que el objeto del derecho administrativo es ambas cosas, esto es, tanto un sujeto como sus funciones ${ }^{36}$; en este caso, parece acogerse ya no un análisis reduccionista, sino holista.

El propósito de este aparte será mostrar las conexiones que han existido entre las tesis o posturas que se han presentado sobre el objeto del derecho administrativo, y el contexto científico, social, económico y político vigente en el momento en que se produjo cada teoría, para plantear que aquello que a veces se muestra como un error, puede ser visto como una conclusión plausible. Para desarrollar el ejercicio propuesto en este aparte se hará uso de la historia y de las periodizaciones habituales en el estudio de la sociedad; por esta razón, siguiendo con la premisa metodológica expuesta en la introducción, el punto central para el estudio será la cosmovisión antes, durante y luego de la Revolución Francesa, hito que tiene conexiones fuertes con la llamada Ilustración.

El estudio de estas conexiones tendrá como objetivo principal ofrecer una perspectiva del derecho administrativo como un sistema que tuvo (1) sus antecedentes previos y (2) su momento de configuración, puesta en marcha y evolución, en constante interacción con los demás sistemas sociales. de las dificultades que examinare en cuantas partes fuere posible y en cuantas requiriese su mejor solución": René DesCARTES, Discurso del método, en Biblioteca de grandes pensadores. Descartes, Madrid, p. 114.

6 Luciano Parejo A., El concepto del derecho administrativo, cit., p. 118. 


\subsection{AnteCEDENTES DEL DERECHO ADMINISTRATIVO}

A continuación se utilizará un gráfico para intentar describir la dinámica del derecho administrativo desde la perspectiva de la diferenciación funcional de los sistemas sociales a lo largo del tiempo. En este se muestran líneas punteadas que podrían entenderse como los antecedentes de lo que puede ser un sistema autónomo, y luego una línea que muestra su continuidad en el tiempo. Se entiende que en la marcha de esta continuidad los sistemas se retroalimentan mutuamente, razón por la cual, por ejemplo, en ciertas épocas el derecho administrativo muestra su interés por el deporte, por la salud, por los medios de comunicación, etc.

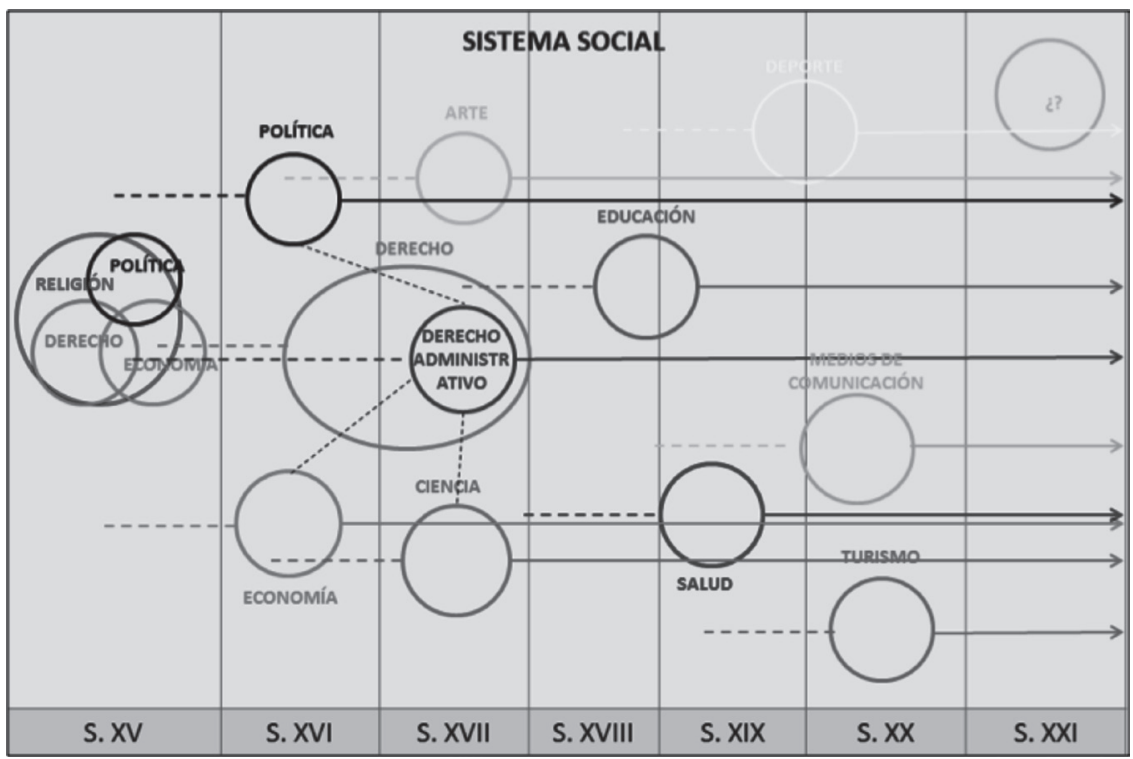

Fuente: elaboración propia, con fundamento en la conferencia de Aldo Mascareño presentada en la Escuela de Sociología de la Universidad Andrés Bello en el primer semestre de 2013.

Ahora, teniendo en cuenta que este aparte se vale en gran medida de periodizaciones históricas y que muchas personas pueden tener objeciones a estas por, en ocasiones, llegar a ser arbitrarias, es necesario integrar a este escrito una aclaración sobre este punto hecha por el historiador del pensamiento científico Alexandre Koyré:

Los cambios imperceptibles desembocan en una diversidad muy clara; de la semilla al árbol no hay saltos; y la continuidad del espectro no hace sus colores menos diversos. Es cierto que la historia de la evolución espiritual de la humanidad presenta una complejidad incompatible con las divisiones tajantes ${ }_{i}$ corrientes de pensamiento se prosiguen durante siglos, se enmarañan, se entrecruzan. [...] Y, sin embargo, la división en períodos no es enteramente artificial. Poco importa que los límites cronológicos de los periodos sean vagos o incluso enmarañados $;$ a una 
cierta distancia, grosso modo, las distinciones aparecen bien claras; y los hombres de una misma época tienen cierto aire de familia ${ }^{37}$.

Con esta explicación se expone el desarrollo de este escrito acudiendo a la historia como herramienta utilizada, no como un microscopio, sino como un telescopio para intentar ver el cosmos en medio del cual se encuentra nuestra materia de interés.

\subsubsection{El pensamiento ¿científico ${ }^{38}$}

Se ha dicho que antes de la edad contemporánea y de la Ilustración, la forma en la que las personas concebían el mundo tenía unos rasgos o características que se pueden identificar ${ }^{39}$. En Occidente, desde la Antigüedad hasta nuestros días, la religión ha tenido una fuerte influencia en la cosmovisión ${ }^{40}$ del ser humano, sobre todo gracias al trabajo de pensadores como Agustín de Hipona y Santo Tomás de Aquino, quienes dieron un trasfondo filosófico a la religión de tal manera que la consolidaron como una forma válida y lógica de explicar el mundo. El logro de este último pensador fue la creación de una síntesis entre la teología cristiana y la ciencia de Aristóteles, formando una totalidad entre el mundo natural, la razón y $\operatorname{Dios}^{41}$.

\subsubsection{La organización social, política y económica en la edad media}

Por esta razón, la Iglesia y el Estado pre-moderno constituían un poder indisoluble, y quien lo cuestionara podría correr la suerte de hombres como Giordano

37 AleXandre, Koyré. Estudios de bistoria del pensamiento científico, Madrid: Siglo XXI Editores, 16. ${ }^{\text {a }}$ ed. en español, 2007, pp. 9 y 10

38 Sostiene Maldonado que "[1]a teología era la ciencia del Medioevo: ciencia de Dios -ciencia de la cual se derivaba cualquier otro conocimiento, o ciencia hacia donde conducían todas las otras ciencias y disciplinas": C. E. MALDONADO, "Qué son las ciencias de la complejidad? Filosofía de la ciencia de la complejidad", en C. E. Maldonado, "Derivas de complejidad. Fundamentos teóricos", Bogotá: UR, 2012, pp. 7-102.

39 "Para ellos, el mundo se experimentaba como una unidad sólida y segura en el que todo se relacionaba como las piezas de un rompecabezas, cada parte en su lugar señalando algún aspecto del plan divino. Nosotros en cambio vivimos en un pluralismo a veces caótico y muy cambiante que no manifiesta ningún sentido claro y evidente. ¿Qué pasó con esa gran síntesis de Sto. Tomás para que llegáramos hoy en día tan transformados?": DARIN MCNABB, La crítica de la razón pura, video, pt. 1/9, 2015, disponible en: https://www.youtube. $\mathrm{com} /$ watch? $\mathrm{v}=5 \mathrm{rUnXN} 3 \mathrm{Srw}$

40 Visión o concepción global del universo. RAE online: http://dle.rae.es/?id=B5j9BD8 En sentido similar, McNabb señala que "[s]i alguien nos hace ver el cosmos de una forma novedosa, entonces lo que nos da es una 'cosmovisión'": cit.

41 Virgilio Ruiz Rodríguez, "Santo Tomás de Aquino en la filosofía del derecho", Claves del Pensamiento, vol. $\mathrm{x}, \mathrm{n} .{ }^{\circ} 19$, enero-junio, 2016, pp. 13-40. 
Bruno o Galileo Galilei. Esto explica por qué - para efectos de nuestro interéssistemas como la religión, la política, la economía y el derecho no estaban funcionalmente diferenciados, la humanidad era normativamente organizada y regida por leyes divinas y el representante de la divinidad en la tierra era el monarca, dueño de todos los bienes y productor de las normas.

\subsubsection{Efectos generales en la configuración del derecho previo al derecho administrativo: la situación que se debía cambiar}

Lo que hoy se conoce con el nombre de propiedad pública era del monarca y las reglas de uso de aquella eran dictadas por y a favor de este ${ }^{42}$. Las vías, los acueductos, los parques, las plazas, etc., desde luego, tenían reglas de administración, pero se trataba, en un primer momento, de la administración del patrimonio de la Corona y, posteriormente, de la polis ${ }^{43}$, pero en estricto sentido no existía la concepción de patrimonio público actual ${ }_{i}$ por consiguiente, no había nada público que administrar y, por lo tanto, al no haber administración "pública", tampoco existía un objeto de conocimiento de esta especialidad del derecho. No obstante, algunos autores reconocen que en esta época el concepto "policía" iría a constituir un antecedente de lo que en la Francia revolucionaria se conoció como derecho administrativo ${ }^{44}$.

En términos generales, las siguientes palabras clave podrían dar un panorama -jurídico y organizacional- de esta época: inexistencia de una conciencia de lo público, ausencia de sometimiento del poder al derecho, absolutismo e irresponsabilidad del monarca. En palabras sistémicas, cabe observar que no podía entenderse configurado un subsistema jurídico-administrativo autónomo con funciones diferenciadas de otros sistemas porque, precisamente, estaba diluido entre un compuesto principalmente religioso, jurídico y político.

Los estudios de la historia indican que cada forma de organización social está en constante cambio hasta llegar a un momento de cambios radicales o

42 "Así, en un principio, la propiedad absoluta del Estado impide desde un punto de vista teórico toda relación con los bienes de uso público. Para los primeros estudiosos de los bienes públicos -y para una parte de la doctrina posterior- ese derecho ilimitado, absoluto, no se adaptaba a la realidad de esos bienes, los iura usus, fructus y abusus no estaban presentes, se trataba de un derecho de guarda y superintendencia. Como consecuencia del mismo hecho, era imposible concebir un verdadero derecho subjetivo de los ciudadanos al uso común, era un derecho político, pero incluso los usos especiales eran considerados como simples favores otorgados por la autoridad encargada de su custodia": Julián Pimiento. Derecho administrativo de bienes, Bogotá: Universidad Externado de Colombia, 2015, p. 41.

43 Para una comparación con el caso alemán que, a propósito, muestra similitudes con el francés, ver Отto Mayer, Derecho administrativo alemán, t. I, Parte general, Buenos Aires: Depalma, 1949, pp. 27 ss.

44 Luciano Parejo A., El concepto, cit., p. 140; Miguel Alejandro Malagón Pinzón, Vivir en policía: una contralectura de los orígenes del derecho administrativo en Colombia, Bogotá: Universidad Externado de Colombia, 2007, pp. 147 ss. 
revolucionarios ${ }^{45}$. Pues bien, este periodo no fue la excepción, y como consecuencia de eventos como la denominada revolución científica de los siglos XVI y XVII, con el trabajo de pensadores como Francis Bacon, Nicolás Copérnico, Galileo Galilei, René Descartes, Isaac Newton y Kant, el estado de cosas comenzó a cambiar.

\subsection{Configuración, PUesta en MARCha \\ Y EVOLUCIÓN DEL DERECHO ADMINISTRATIVO}

El denominado pensamiento científico entró en escena y comenzó a erosionar las bases de la sabiduría escolástica, y así mismo influiría en todas las áreas del conocimiento, inspirando los ideales de la Revolución Francesa y el derecho que vendría con esta.

\subsubsection{El pensamiento científico}

Las obras de los primeros científicos ${ }^{46}$ trajeron un cambio de paradigma: se pasó de la concepción del mundo explicado a partir de leyes divinas a una visión explicativa más sencilla: el mundo es materia en movimiento; esta es una de las premisas esenciales de este pensamiento y es atribuida a "la filosofía mecánica, también denominada corpuscular, que orienta de manera decisiva los desarrollos del quehacer científico y filosófico de ese período ${ }^{\prime 47}$. Acudiendo a las metáforas propias de este contexto, se concibió el universo como un mecanismo de relojería ${ }^{48}$ a gran escala, en donde la piñonería es la

45 Ver Thomas S. Kunn, La estructura de las revoluciones cientificas, Ensayo preliminar de Ian Hacking, Carlos Solís Santos (trad. e introd.), Denis Peña (trad. del ensayo), México, Fondo de Cultura Económica, 4. ${ }^{a}$ ed., 2013.

46 Ha sido relativamente claro - para quienes se acogen a la tesis del nacimiento del derecho administrativo en Francia- cuál fue la razón política y social que acompañó el surgimiento de este derecho especiali sin embargo, en la mayoría de dichos estudios jurídicos no se observa mucho énfasis en el estudio de la estructura del pensamiento científico que estuvo detrás de estas razones, lo cual es comprensible, teniendo en cuenta el carácter especializado que han venido adquiriendo las áreas de conocimiento, principalmente a partir del siglo Xx. Ante esta situación se considera importante tratar de realizar un breve acercamiento a las premisas básicas del pensamiento científico de la Ilustración.

47 Leticia Rocha Herrera, "Descartes y el significado de la filosofía mecanicista", Revista Digital Universitaria, 10 de abril 2004, vol. 5, n. ${ }^{\circ}$ 3, pp. 3-16.

48 "Tomando como ejemplo el reloj, podía entenderse el conocimiento del todo a partir del conocimiento de las partes. Eso significaba que el todo, el sistema, estaría completamente explicado sólo cuando fuese posible ir dando cuenta del proceso lineal, de la transición (por ejemplo, del movimiento mecánico) de una parte del sistema a otro (cf. 1961b, p. 57)": Francisco Javier SerRano-Bosquet y Gustavo Caponi, "Warren Weaver y el Programa de Biología Experimental de la Fundación Rockefeller", Sci. stud., vol. 12, n. ${ }^{\circ}$ 1, 2014, pp. 137-167. Disponible online [consultado el 03-26-2017]. 
materia y estos piñones se transmiten mutuamente el movimiento, el cual no es aleatorio, sino que está regido por leyes matemáticas ${ }^{49}$, ya no divinas, sino humanas y universales. Y en donde el método que se utilizaría "para hacer ciencia consiste en aislar y simplificar un problema lo más posible, para así poder formalizar matemáticamente y encontrar una solución" ${ }^{\prime 50}$. Desde este momento, la ciencia comenzó a dividirse en disciplinas cerradas, en donde cada una "se caracteriza(ba) por tener un método propio, un lenguaje, una tradición, un ámbito y un modo propio de organización" ${ }^{\prime 1}$.

\subsubsection{La organización social, política y económica en la edad moderna}

Esta visión mecanicista y corpuscular del mundo -cuyo principal exponente fue René Descartes- implicaría que el conocer de cualquier objeto de estudio se realizaría a través de la reducción de sus componentes que, a su vez, tendrían su explicación en función del gran reloj ${ }^{52}$. Pues bien, al parecer, los teóricos de la Ilustración, esencialmente en Francia, no fueron ajenos a esta cosmovisión, y esta influencia puede verse en la nueva forma de comprensión y configuración del Leviatán ${ }^{53}$, entendido como ese gran aparato con poderes -a modo de piezas de relojería- fácilmente identificables.

Como reacción al estado de cosas del paradigma que precedió a la Revolución, se configuró un nuevo orden social, económico, político y jurídico, y el diseño estatal que se reflejó en Francia parece inspirado por el pensamien-

49 Diego Aisa, "La filosofía mecánica de Descartes, Boyle y Huygens", en La filosofía de los científicos, Universidad de Zaragoza, 1995, pp. 83-131. Disponible en: http://institucional. us.es/revistas/themata/14/05\%20Aisa.pdf

50 Carlos Gershenson, "Enfrentando a la complejidad: predecir vs. adaptar", Universidad Nacional Autónoma de México y Vrije Universiteit Brussel, 2009, p. 1.

51 C. E. Maldonado, "Qué son las ciencias de la complejidad? Filosofía de la ciencia de la complejidad", cit., pp. 89 ss.

52 Vale la pena aclarar que, desde una perspectiva actual, en un texto que se supone trata de derecho, contemplar argumentos científicos, matemáticos y físicos puede resultar extraño, lo cual es comprensible debido a la diferenciación entre disciplinas y la alta especialización que se ha producido en todas las áreas de conocimiento. No obstante, es necesario destacar que incluso en la edad moderna los saberes no estaban tan diferenciados como hoy. No era extraño encontrar pensadores que eran, a la vez, filósofos, físicos, matemáticos, médicos, políticos, etc. De hecho, Descartes, reconocido normalmente como filósofo, matemático y físico francés, también "cursó estudios de Derecho en la Universidad de Poitiers, donde obtuvo la licenciatura en 1616": Cirilo Flórez Miguel, "René Descartes. La constitución de la Modernidad", en Biblioteca de grandes pensadores, Madrid: Gredos, 2011, p. XIII. No debe extrañar entonces que las ideas de los científicos de esta época se vieran reflejadas y hubieran servido de base tanto al discurso filosófico que inspiró a la Revolución Francesa como a las premisas de organización social que se derivaron de la misma.

53 Jacques Chevallier, El Estado posmoderno, Bogotá: Universidad Externado de Colombia, 2011, p. 19. 
to científico de la Ilustración ${ }^{54}$, esto es, leyes derivadas de la razón humana, deducidas por medio de un método de estudio reduccionista que, a su vez, se refleja en la configuración del poder que ya no sería unitario, sino que sería diseccionado en sus partes consideradas elementales para buscar un equilibrio en el gran cuerpo estata $1^{55}$. Chevallier expone con claridad, dentro de los cambios esenciales, "el culto a la Razón reemplaza la obediencia debida a los dioses y la sumisión a las leyes de la naturaleza"56, e igualmente "la preminencia acordada al individuo, situado en el centro de la organización social y política" ${ }^{\prime \prime 7}$. Desde el punto de vista económico el individuo adquiere amplias libertades y el derecho se convierte en una eficaz herramienta para protegerlas ${ }^{58}$.

Esta cosmovisión resultó ser - por su simplicidad- bastante atractiva, y así se fue construyendo el nuevo derecho de la organización estatal de la época. Si hay un gran órgano, que funciona a través de poderes, cada uno de esos poderes -según el principio de legalidad- debía tener unas reglas de juego; en concordancia con esto, las reglas del juego del poder ejecutivo irían a conformar lo que sería el droit administratif ${ }^{59}$.

\subsubsection{Efectos generales en la configuración del derecho administrativo: nuevo subsistema jurídico autónomo con funciones diferenciadas en constante evolución}

Los antecedentes que generaron el surgimiento de esta nueva forma de organización social, es decir, del Estado sometido al derecho, de alguna manera

Es con la Rev

Ibíd., p. 18

Ibíd., p. 18. como principio fundante (Carré De Malberg...) de la nación francesa, al lado de la igualdad y la legalidad, la separación de los poderes que antes detentaba un solo sujeto; desde ese momento histórico el poder ya no sería del monarca sino del pueblo, y sería ejercido a través de distintos órganos para evitar el absolutismo. Se diferenciaron entonces tres poderes: el legislativo, el judicial y el ejecutivo, y la existencia de este último, al que se le encargó como misión esencial llevar a cabo las acciones necesarias para materializar lo dispuesto por la ley, permitió, según estas teorías, identificar el objeto del derecho administrativo, que sería por lo tanto el conjunto normativo que iría a regir la actividad de este nuevo poder ejecutivo.

JaCQues CHEVAlLIer, El Estado posmoderno, cit., p. 17.

Niklas Luhmann, El derecho de la sociedad, cit., p. 328.

Santofimio cita a Parejo para destacar que "el criterio en cuestión, además de ser uno de los primeros con que se pretendía explicar el derecho administrativo, posee indiscutibles raíces en el derecho del anterior régimen, que dicho sea, llevaba muy pocos años desaparecido": Jaime Orlando SANTOfimio Gamboa, Tratado de derecho administrativo, cit., p. 49 , nota 34. En el mismo sentido, Oril Mirpuig señala: "Durante los dos primeros tercios del siglo XIX (esto es, en los primeros momentos del Derecho administrativo como ciencia, cuando surgieron las primeras definiciones de este sector del ordenamiento jurídico) predominaron las concepciones orgánicas": Oriol Mir PuigPelat, "El concepto de derecho administrativo desde una perspectiva lingüística y constitucional", cit., p. 63. 
indicaban el objetivo o política pública que este aparato debía perseguir y, $_{\text {, }}$ como se trataba de un nuevo aparato, debía pasar por un proceso de configuración, puesta en marcha, consolidación y enfrentamiento a cambios o evolución, proceso que, desde luego, consecuentemente surtieron sus funciones y su estructura y, por consiguiente, también el régimen jurídico de las mismas.

Se revisará brevemente este proceso dentro de un periodo que -aproximadamente-comienza con la Revolución Francesa, sigue en el siglo XIX y va hasta mediados del $\mathrm{xx}_{\text {; }}$ para cumplir con esta revisión, es posible orientarse con los periodos que algunos autores ${ }^{60}$ exponen, en los que muestran los distintos fines o política pública que el Estado ha asumido a lo largo de la historia y destacan cómo, en cada periodo correspondiente, la función y estructura administrativa cambia en coherencia con estos fines.

- Periodo de configuración. Finales del siglo XVIII y comienzos del siglo XIX (1789-1800). En un primer momento de la época revolucionaria, que puede llamarse de configuración, el Estado comienza a conformar su estructura, por lo tanto, su manifestación y esfuerzos estarían concentrados en este objetivo. En este periodo podría ubicarse el naciente Estado de derecho.

- Periodo de puesta en marcha. Entre comienzos del siglo XIX y su primera mitad (1800-1850) puede identificarse una puesta en marcha del Estado, en donde los esfuerzos pasan al mantenimiento del orden público y de la seguridad de los ciudadanos y su intervención "se limitará a establecer un marco genérico y formal en la configuración del orden económico y social ${ }_{i}$ después, este orden económico-social será desarrollado, será llenado de utilidades concretas por los ciudadanos, por la iniciativa privada"; ; en este periodo el Estado es calificado como liberal ${ }^{61}$.

- Periodo de evolución. Entre el último tercio del siglo XIX y la primera mitad del siglo Xx (1860-1950)62, el Estado comenzaría su evolución de acuerdo con los cambios sociales. La actitud de mínima intervención del aparato estatal contribuyó a la generación de problemas sociales que forzó al Estado a dejar

60 Ver, entre otros, JaCQues Chevallier, El Estado posmoderno, cit., y GaSPAR Ariño O., Principios de derecho público económico. Modelo de Estado, gestión pública, regulación económica, Bogotá: Universidad Externado de Colombia, 2003.

61 Ibíd., p. 288.

62 "Durante el último tercio del siglo XIX y la primera mitad del siglo XX -la 'edad de oro' de la ciencia del Derecho administrativo, 'la época de las catedrales' doctrinales (51)- primaron, en cambio, las tesis objetivo-funcionales. Fue entonces cuando E. Laferrière, Duguit, Jèze y Hauriou, en Francia ${ }_{i}$ Orlando, en Italia, y Otto Mayer y Forsthoff, en Alemania, vincularon el Derecho administrativo a criterios funcionales como, respectivamente, los actos de autoridad (52), el servicio público (53), la prerrogativa (54), la actividad del Estado dirigida a la satisfacción de sus propios fines (55), la actividad estatal distinta de la actividad legislativa y de la judicial (56) y la procura existencial (Daseinsvorsorge) (57) (58)": ORIOL Mir PuigPelat, "El concepto de derecho administrativo desde una perspectiva lingüística y constitucional", cit., p. 63. 
su posición neutral e intervenir directamente en los asuntos socioeconómicos, generándose "el consecuente crecimiento exponencial en cantidad e intensidad de las funciones públicas como manifestación más visible"63. En esta fase, enmarcada por Ariño entre 1930 y 1980, el Estado es adjetivado como social y de derecho.

Si se hace un contraste entre estos tres periodos o fases-denominados de configuración, puesta en marcha y evolución-con las tres teorías -subjetivas, objetivas y mixtas- que se han expuesto tradicionalmente para explicar el objeto del derecho administrativo, puede notarse que hay varias coincidencias entre los primeros y las segundas.

En ese sentido, en la fase de configuración del derecho administrativo se presentó la tesis subjetiva, probablemente porque los estudiosos de ese momento ${ }^{64}$ estaban conociendo, como principal política pública, el interés de la sociedad en someter el poder al derecho; contagiados con el pensamiento científico reduccionista y de la Ilustración ${ }^{65}$, los teóricos de la época entendieron que una de las formas para lograr este control era separando, reduciendo -en tres partes-el poder que antes estaba en cabeza del monarca ${ }^{66}$, y unas de esas partes se denominó poder Ejecutivo. En consecuencia, para darle existencia práctica e institucional a este poder, el Estado realizó contundentes manifestaciones para la estructuración de dicha rama ${ }^{67}$, que nacía con la misión especial de ejecutar

63 Luciano Parejo A., Lecciones de derecho administrativo, Universidad Externado de Colombia y Tirant lo Blanch, 2011, p. 23.

64 Macarel, Colmeiro, Cormenin y De Gerando fueron los principales autores que representaron posiciones subjetivas y, en síntesis, al parecer, conscientes del nuevo paradigma político y jurídico que trajo consigo la Revolución Francesa; especialmente a partir de la separación de poderes, identificaron como objeto del derecho administrativo aquellas manifestaciones y actividades propias del ejecutivo. Ver Juan Carlos Covilla Martínez, "Identificación de la función administrativa", cit. p. 172; Luciano, Parejo A., El concepto del derecho administrativo, cit., p. 180; Jaime Orlando Santofimio Gamboa, Tratado de derecho administrativo, cit., p. 49.

65 "En él es básica la idea del equilibrio, común al pensamiento dieciochesco científico y filosófico, que, como señala Schmitt, une a Montesquieu, a través de Bolingbroke, con el mercantilismo, los fisiócratas, la física de Newton o la psicología de Shaftesbury. En cualquier caso, Montesquieu suministró la formulación más perenne a la teoría de la división de poderes": Juan José Solozábal EchavarRía, "Sobre el principio de separación de poderes", Revista de Estudios Políticos, n. ${ }^{\circ} 24,1981$, p. 221.

66 "Como es sabido el pensamiento político durante la época absolutista abandonó la idea del gobierno mixto -por ejemplo, Bodino-, confiriendo al rey el poder de donner et casser la loi. Un sector, como diríamos hoy, contestatario, sin embargo, insistía en conferir al monarca el papel secundario que preconizara Marsilio de Padua. Para los monarcómacos, en efecto, el rey es considerado como minister, cusías, executor legum": ibíd., p. 218.

67 Desde un punto de vista sociológico, explica Luhmann, "el análisis funcional encuentra sus constantes en funciones, no en estructuras. No obstante, muchas funciones pueden ser dependientes de estructuras". En concordancia con la función -o una de las esenciales-que parecía ser protagonista en el naciente Estado de derecho, es ilustradora la continuación de la idea anterior, pues Luhmann destaca dos formas de ver la función, como "función 
la ley y garantizar la libertad individual. El protagonista en este periodo fue un sujeto especial llamado administración pública.

Una vez se configuró el derecho administrativo, comenzó su puesta en marcha y los teóricos observaron que el centro de atención o la política pública pasó de la estructura o sujeto -que no se abandonó pero que ya se daba por sentado- a las funciones de este, es decir, a una intervención estatal, ya no solo garantizando un marco para la libertad económica, sino prestando servicios públicos, e incluso actuando como un particular en ejercicio de su libertad económica. Esta situación sirvió de muestra empírica para las tesis objetivas que, a su vez, se estructuraron centrándose, bien en las características del medio de intervención estatal (poder), o bien en el fin de la misma (servicios públicos). Para cumplir con esta política, el Estado requirió la creación de una estructura-empresas- para prestar servicios públicos y otras actividades económicas.

Posteriormente, el derecho administrativo comenzó su evolución, tratando de ir en sintonía con los avances de la sociedad (economía, tecnología, ciencia, etc.) que, a su vez, ponía en evidencia la incapacidad de un pensamiento reduccionista para explicarla. La práctica comenzó a mostrar un complejo de interacciones entre agentes, cuya actividad no podía encajarse claramente en las categorías tradicionales: se encontraban autoridades estatales ejerciendo actividades típicamente administrativas pero, a la vez, ejecutando actividades típicamente económicas, y adicionalmente aparecieron sujetos privados ejerciendo funciones administrativas. Este fue el enmarañado panorama que observaron los estudiosos de este momento y, ante semejante desconfiguración de la ecuación inicial (sujeto especial = derecho administrativo / función administrativa $=$ derecho administrativo), optaron por acudir a tesis mixtas, es decir, asumiendo que el objeto del derecho administrativo era la administración pública entendida como sujeto y como función. Desde el punto de vista del pensamiento científico esto coincide con la crisis del reduccionismo y la tendencia al holismo que parece comenzar a incidir en la sociedad actual.

En conclusión, lo que se ha podido observar es que cada cambio en el derecho administrativo y su objeto está interconectado con cambios que suceden en su entorno, es decir, en otros sistemas como el social, el científico, el político y el económico. Esta conclusión-como se anunció en la introducción- pretende ofrecer una visión alternativa a la de considerar a los criterios de explicación

de la construcción del sistema en general y por la función de la estructura a secas". Con esta distinción, podría pensarse que en la Francia revolucionaria, durante el surgimiento de las tesis subjetivas para explicar el derecho administrativo, la función principal era la de construir un nuevo orden institucional. Luego de esto, la atención se centraría en las funciones, no de construcción de esta estructura, sino en las funciones de las propias estructuras construidas. Ver NikLas LuHMAnN, Sociología política, Madrid: Trotta, 2014, p. 28. 
del derecho administrativo como errados y/o válidos. A su vez, está visión alternativa también será puesta a prueba para presentar un breve acercamiento a lo que algunos estudios califican como una nueva configuración social que parece estremecer los cimientos más profundos del mismo derecho administrativo. Esta razón es más que suficiente para acercarse a las características de este nuevo orden social y tratar de entender qué es lo que está cambiando alrededor de esta especialidad jurídica.

\section{RASGOS DE UN NUEVO ORDEN SOCIAL. ¿HACIA LA RECONFIGURACIÓN DEL SUBSISTEMA JURÍDICO-ADMINISTRATIVO?}

El propósito de este capítulo es describir lo que se ha considerado una nueva etapa de la sociedad, con el objetivo de intentar identificar cómo este fenómeno podría generar una reconfiguración en el objeto del derecho administrativo ${ }^{68}$. Para cumplir con este objetivo se continuará con la misma metodología del capítulo anterior; en consecuencia, se estudiará el (3.1) pensamiento científico actual, (3.2) la organización social, política y económica posmoderna, y (3.3) los efectos que estos sistemas están generando en el derecho administrativo.

\subsection{Pensamiento Científico: TeOría de sistemas, COMplejidad y ReGulación}

A partir de mediados del siglo XX, el pensamiento científico ha mostrado un cambio que va del reduccionismo al holismo, es decir, de la tendencia metodológica que busca comprender los fenómenos desde el análisis de sus partes ${ }^{69}$,

68 A pesar de la intención propuesta, será necesario advertir que en esta oportunidad y con el espacio disponible es difícil sacar conclusiones contundentes, sobre todo en semejante area de estudio. Tan solo se pretende realizar una aproximación a lo que podrían ser los inicios de una investigación más compleja y rigurosa.

69 El método reduccionista, derivado del pensamiento científico revolucionario, resultó ser altamente exitoso en varios campos del saber. A manera de ejemplo, Gershenson señala que "la ley de la gravitación universal describe cómo es que se atraen dos cuerpos celestes. No quiere decir que en nuestro sistema solar haya solo dos cuerpos celestes, pero es suficiente describir cómo el sol atrae a planetas, asteroides y cometas. Obviamente, hay interacciones entre planetas y asteroides, pero estos, para fines prácticos, se pueden ignorar". Continúa con otro ejemplo práctico, esta vez en el campo de la medicina, destacando cómo "[h]asta hace poco la mayoría de las muertes en humanos eran causadas por enfermedades infecciosas originadas por virus, bacterias, hongos o por parásitos. $\mathrm{Al}$ haber una causa principal de una enfermedad infecciosa esta puede combatirse 'simplemente' atacando al agente con medicamentos, o bien previniendo su propagación ya sea con medidas de higiene o vacunación". No obstante, cuando los fenómenos a estudiar no podían aislarse por presentar componentes con interacciones relevantes, el reduccionismo comenzó a presentar falencias y, precisamente, uno de los campos en el que el estudio o la importancia de las interacciones entre componentes es relevante es el campo de las 
hacia la tendencia que se centra en estudiar las conexiones e interacciones entre dichas partes para comprender el todo que estas conforman y que es diferente de cada una de ellas individualmente considerada. Dentro de este último tipo de enfoque metodológico se encuentra la teoría general de sistemas y sus versiones más elaboradas, que incluyen los conceptos de incertidumbre y complejidad y que, en honor a este último concepto, se han denominado teorías de sistemas complejos ${ }^{70}$, las cuales, a su vez, describen realidades complejas.

Para comenzar un acercamiento a estos nuevos enfoques teóricos es útil conocer el significado etimológico de la palabra complejo ${ }^{71}$. Esta palabra viene del latín complexus ${ }^{72}$, que quiere decir entrelazado o entretejido, lo que da una idea de lo que estudia este método, esto es, interacciones entre elementos. Se dice que un fenómeno es complejo cuando tiene componentes difíciles de separar, y esto ocurre -explica Gershenson- cuando una interacción determina, aunque sea parcialmente, el futuro de los componentes del fenómeno estudiado. El mismo autor cita como ejemplo el caso de una partida de ajedrez, en donde la movida de cada jugador dependerá parcialmente de la jugada del otro jugador y viceversa. Por consiguiente, no puede predecirse completamente el futuro de un fenómeno complejo si se estudian solo sus elementos (como lo hace el método reduccionista); por esta razón es que en este enfoque teórico las interacciones son relevantes ${ }^{73}$. Pero, no solo el ejemplo descrito caracte-

ciencias sociales (mercados de valores, sistemas de transporte, publicidad, derecho, etc.). Ver Carlos Gershenson, Curso "Pensamiento Científico", de la Universidad Nacional Autónoma de México. Disponible en: https://es.coursera.org/learn/ciencia

70 Explica Carlos Maldonado: "Existen dos grandes comprensiones de complejidad, usualmente indiferentes entre sí, distantes incluso, y quizás radicalmente distintas. De un lado, la complejidad como ciencia, y de otra parte, la complejidad como método. Resulta más apropiado referirnos a la primera como las ciencias de la complejidad o también, más prudentemente, como el estudio de los sistemas complejos adaptativos. En cuanto a la segunda concepción, es conocida genéricamente como el pensamiento complejo. Mientras que la primera hace referencia a diversos, incluso numerosos autores y líneas de trabajo e investigación, en el segundo caso se trata prioritariamente de la obra de un autor, aunque sean numerosos sus seguidores y epígonos": Carlos E. Maldonado, Complejidad: ciencia, pensamiento y aplicación, Bogotá: Universidad Externado de Colombia, 2007, p. 19.

71 Antes del siglo XX, la palabra "complejo" tenía una connotación peyorativa.

72 RAE: http://dle.rae.es/?id=A1JK3tM

73 "La 'complejidad' constituye una perspectiva novedosa y marginal en la ciencia contemporánea; su carácter de novedad radica en que el estudio de la complejidad implica, en buena medida, un quiebre o discontinuidad en la historia de la ciencia o, más precisamente dicho, en la racionalidad científica occidental. La complejidad introduce, en el terreno de las ciencias, una racionalidad post-clásica que habilita e incorpora problemas ignorados o vedados por el pensamiento científico moderno. Estos problemas involucran, en un sentido no exhaustivo, cuestiones relativas al desorden, el caos, la no-linealidad, el noequilibro, la indecidibilidad, la incertidumbre, la contradicción, el azar, la temporalidad, la emergencia, la auto-organización. La complejidad puede entenderse, por lo tanto, como un paradigma científico emergente que involucra un nuevo modo de hacer y entender la ciencia, extendiendo los límites y criterios de cientificidad, más allá de las fronteras de 
riza un fenómeno complejo. Modelos de sistemas complejos los constituyen la economía, el mercado de valores, el medio ambiente, las redes sociales, el tráfico urbano $\mathrm{y}$, por supuesto, el gran meta-sistema: la sociedad, objeto de estudio por excelencia del derecho. Pero, el pensamiento científico adscrito a la teoría de los sistemas no se limita a describir la complejidad, también se ha planteado una manera de enfrentarla, y los estudios ${ }^{74}$ realizados -desde mediados del siglo XX- para este propósito se conocen bajo el nombre de cibernética.

La cibernética, palabra proveniente del griego kybernētiké que significa el "arte de gobernar una nave" el control de los sistemas (biológicos, sociales, mecánicos, etc. ${ }^{76}$. Desde el nacimiento de esta disciplina se aclaró que su aplicación no estaba limitada a ningún campo de estudio específico y que, por ejemplo, "la corteza cerebral del organismo de vida libre, el hormiguero encarado como una sociedad en funcionamiento, o el sistema económico humano, son notables por su importancia práctica y por la imposibilidad de ser estudiados acudiendo a los métodos antiguos ${ }^{1177}$. El propósito general de la cibernética, entonces, es determinar cómo los distintos sistemas mantienen su estabilidad en un ambiente en el que hay constante flujo de entrada y salida de información, en pocas palabras, cómo son regulados ${ }^{78}$.

Ahora, vale la pena destacar que estas teorías no han surgido espontáneamente, sino en interacción con su materia de estudio, en este caso, la sociedad actual. En ese sentido es importante describir cómo se manifiesta la correspondencia entre el pensamiento científico descrito y fenómenos sociales actuales.

\subsection{LA ORGANIZACIÓN SOCIAL, POLÍTICA Y ECONÓMICA EN LA ACTUALIDAD}

La organización social, económica y política de la era moderna confluyó en un muy exitoso modelo: el Estado. Afirma Chevallier que "todas las entidades políticas se adaptaron al molde estatal, no hay otra alternativa diferente a la del Estado, que, al ser un emblema de la modernidad, parece agotar las

la ciencia moderna, ancladas sobre los principios rectores del mecanicismo, el reduccionismo y el determinismo (Delgado Díaz 2004; Morin 2004b; Sotolongo y Delgado Díaz 2006, Vilar 1997)": Leonardo G. Rodríguez Zoya y Julio Leónidas Aguirre, "Teorías de la complejidad y ciencias sociales. Nuevas estrategias epistemológicas y metodológicas", Nómadas. Revista Crítica de Ciencias Sociales y Jurídicas, 30, 2011, 2, p. 2.

78 Ver ibíd., pp. 332 ss. También Fritjof CAPRA, La trama de la vida: una nueva perspectiva de los sistemas vivos, Barcelona: Anagrama, 2009, pp. 70 ss. 
posibilidades imaginables y aparece como la única alternativa posible ${ }^{\prime \prime 79}$. Sin embargo -debido al estrecho vínculo entre sociedad y Estado-, los cimientos sobre los que se construyó el Estado moderno han comenzado a moverse en la medida en que la sociedad moderna -al igual que el pensamiento científico- también lo está haciendo.

Algunos autores han sostenido que actualmente vivimos en la era de la posmodernidad, sin embargo, no hay un concepto o un acuerdo pacífico de lo que esta palabra significa. A pesar de esto, sí es posible encontrar algunas características de la sociedad actual -o posmoderna, si se quiere-que difieren de algunos postulados de la era de la sociedad que se comenzó a estructurar luego de la Revolución Francesa. En ese sentido, las siguientes son las características ${ }^{80}$ principales que se destacan de la sociedad actual:

- Se presenta una crisis en dos de los postulados clave con los que se avanzó en la sociedad moderna: la predicción y la certidumbre. Por un lado, la eficacia de la formulación de leyes universales para predecir el futuro ha entrado en crisis debido a que buena parte de los objetos de estudio cambian con una rapidez que era impensable en la edad moderna. Por otro lado, y relacionado con lo anterior, el deseo de certidumbre, por ser considerado como excluyente de la diversidad y la pluralidad, se comienza a reemplazar por el postulado de la incertidumbre como forma que favorece el libre albedrío ${ }^{81}{ }_{i}$

- La sociedad actual se encuentra mundialmente conectada, incluso de manera instantanea, a través de distintos tipos de redes. Esto rompe con la distinción entre temas internos y externos de las sociedades estatales de la modernidad $^{82}$;

- Existe interdependencia entre los miembros, agentes y sistemas sociales. Esto implica que lo que le ocurre a un ciudadano o a una institución, normalmente produce efectos o consecuencias en otros ciudadanos o instituciones ${ }^{83}$;

80 Se han tomado de varias obras que tratan el tema de la posmodernidad desde el punto de vista sociológico, político, científico, entre otros. Ver JeAn-Francois LyOtaRD, ¿Por qué filosofar? Cuatro conferencias, Barcelona: Paidós, 1989, pp. 62 ss.; JACQues CheVAlLIER, El Estado posmoderno, cit.; Manuel Castells, La sociedad red, Madrid: Alianza Editorial, 1997; José G. Vargas-Hernández, "Perspectivas de la posmodernidad institucional", Cuadernos de Filosofía Latinoamericana, vol. 32, n. ${ }^{\circ}$ 104, 2011, p. 123; José Fernando Flórez Ruiz, "De Maquiavelo al Estado postmoderno. Paradigmas políticos de aproximación al fenómeno estatal", Revista Derecho del Estado, n. ${ }^{\circ} 29$, julio-diciembre, 2012, p. 109; José Guillermo FOuCE, "Frente a la posmodernidad", Fundamentos en bumanidades, Universidad Nacional de San Luis n. ${ }^{\circ}$ II, 1/2000, pp. 77-110; W. R. Daros, "Crisis, licuefacción de los valores y fragilidad de las relaciones en la posmodernidad según Zygmunt Bauman", Estudios Filosóficos LXIV, 2015, pp. 281-298; Robert COOPER, "El Estado posmoderno", Revista Académica de Relaciones Internacionales, n. ${ }^{\circ}$ 1, GERI-UAM, marzo, 2005.

81 Ilya Prigogine, El fin de las certidumbres. Barcelona: Taurus, 1997, p. 12.

82 Manuel Castells, La sociedad red, cit.

83 Ibíd. 
- Cambia el interés en la explotación de los tres sectores tradicionales ${ }^{84}$ de la economía y se centra en la economía basada en la información y en el conocimiento ${ }^{85}$;

- Se presentan rápidos avances en materia tecnológica y científica, los cuales son explotados económicamente, pero a la vez se observa una toma de conciencia o preocupación por la naturaleza y el medio ambiente.

Estas características, obviamente, no son las únicas, y tampoco se afirma que no hayan aparecido de manera aislada en otras épocas; sin embargo -como se verá más adelante-, en su conjunto, se han proyectado en los fundamentos del derecho moderno de tal manera que parecen dar paso a un nuevo

... derecho 'intervencionista' (Luhmann), concebido como un instrumento de acción en manos del Estado, puesto al servicio de la realización de políticas públicas (Morand 1999) y destinado no solo a delimitar los comportamientos sino a lograr ciertos objetivos y a producir algunos efectos económicos y sociales; mientras que el derecho moderno, 'de tipo formal', garantizaba la autonomía de los actores sociales, este nuevo derecho, 'de tipo material' y 'de tipo reflexivo' (Teubner), manifestaría los 'objetivos reguladores', con la pretensión de actuar sobre los equilibrios sociales ${ }^{86}$.

En consecuencia, puede verse que el pensamiento científico expuesto guarda correspondencia con el contexto social, político y económico anteriormente descrito. Esta relación de correspondencia también parece comprender al derecho, pero sobre todo, al derecho administrativo debido a que esta disciplina se constituye en una herramienta que permite la materialización de la política

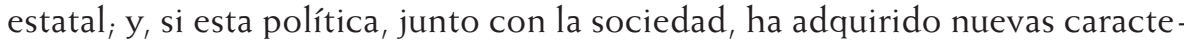
rísticas, es importante ver qué efectos se generan en el derecho administrativo.

\subsection{EFectos generales EN LA CONFIGURACiÓN \\ DEL SUBSISTEMA JURÍDICO-ADMINISTRATIVO}

Para analizar los efectos que producen el pensamiento científico y la dinámica de la sociedad actual en el derecho administrativo, es necesario identificar los cimientos esenciales de esta disciplina para ver cómo están siendo afectados. En ese sentido, será importante hacer una breve descripción de tales cimientos

84 Primario: agricultura y ganadería ${ }_{i}$ secundario: manufactura e industria; terciario: servicios.

85 Carlos E. Maldonado, "Política y sistemas nolineales: la biopolítica", en Dilemas de la política, Bernardo Vela Orbegozo (coord.), Bogotá: Universidad Externado de Colombia, 2007, pp. 91-142.

86 JaCQues Chevallier, El Estado posmoderno, cit., p. 179. 
y analizar cómo han entrado en crisis, para, posteriormente, plantear algunos cuestionamientos que sirvan de base para una futura investigación.

\subsubsection{Principio de separación de poderes}

El principio de separación de poderes, que dio origen formal a las ramas ejecutiva, legislativa y judicial, permitió que el derecho administrativo -en Francia-, en sus inicios, tomara autonomía como disciplina especializada del derecho por tener un ámbito de aplicación relativamente claro: la Rama Ejecutiva. Toda actividad proveniente o relacionada con esta rama se regía por normas de derecho administrativo. Ahora, es cierto que la separación de poderes ha recibido críticas, incluso desde su implantación ${ }^{87}$, y así mismo que en el devenir de la práctica administrativa se han conocido experiencias jurídicas que no obedecían a la lógica de este principio, como por ejemplo, que ramas diferentes de la ejecutiva excepcionalmente desempeñaran funciones administrativas $^{88}$. Sin embargo, en los últimos años resulta cada vez más difícil intentar aplicar este principio teniendo en cuenta la presencia de fenómenos que lo desdibujan, pues, ya no solo han tenido que ampliarse las fronteras del concepto de administración pública para abarcar a sujetos diferentes de la Rama Ejecutiva, sino que hay fenómenos que ya no encajan en la estructura de este principio. De manera enunciativa, a continuación se describen algunos casos del derecho colombiano ${ }^{89}$.

Es posible evidenciar que, desde hace varios años, la Rama Ejecutiva desarrolla actividades típicas tanto de la Rama Legislativa (producir normas generales y abstractas) ${ }^{90}$ como de la Rama Judicial (resolver controversias) y, a su vez, la Rama Judicial desarrolla, no solo labores ejecutivas, sino también materialmente de legislación (sentencias de la Corte Constitucional y del Consejo de Estado sobre el Río Bogotá); y en el mismo sentido se ha visto que la Rama Legislativa en algunos casos actúa como administrador y en otros

87 "... lo que impropiamente se llama separación de poderes, no es más que la diversidad de participación, el diferente modo de actuar de los diversos órganos, en la actividad general del Estado": LEÓN Duguit, Manual de derecho constitucional, Madrid: Librería Española y Extranjera, 1926, p. 156.

88 Fenómenos como "la asunción de funciones administrativas por parte de las otras dos ramas del poder público, así como por particulares, han traído consigo la dificultad de sustentar esta justificación del derecho administrativo": Alberto Montaña Plata, Fundamentos de derecho administrativo, Bogotá: Universidad Externado de Colombia, 2010, p. 43.

89 Como lo describe Montaña, desde sus inicios nuestras construcciones jurídico-administrativas se inspiraron en el derecho francés. Alberto Montaña Plata, La dimensión teórica de la jurisdicción contencioso administrativa, Bogotá: Universidad Externado de Colombia, 2005, p. 86.

90 R. Carré de MalberG, Teoría general del Estado, México: Fondo de Cultura Económica, 1998, p. 428. 
como juez. Desde luego, los defensores del dogma de la separación de poderes explican que estos casos, como los anteriormente mencionados, no son más que excepciones permitidas por el sistema normativo que lo que hacen es confirmar la regla general. No obstante, esas excepciones parecen aumentar progresivamente y reflejarse tanto en la estructura de la administración pública como en las funciones de las entidades estatales.

También se puede comprobar que desde hace varios años existen alrededor de cuarenta ${ }^{91}$ órganos estatales con diferente denominación (comisiones, consejos, comités, etc.) que se integran, en algunos casos, con miembros, no solo de las tres ramas del poder público, sino además con órganos que no pertenecen a estas, e incluso con organizaciones privadas. Es decir, existen órganos impensables para la categoría organizacional derivada del principio de separación de poderes francés acogido en nuestro derecho. Podría decirse que se trata de órganos asesores o de coordinación, sin embargo, la mayoría de estos terminan incidiendo en la toma de decisiones de las entidades que los integran.

Por otro lado, dentro de los temas más debatidos recientemente en la doctrina y en la jurisprudencia se encuentran los relacionados con los órganos autónomos de carácter constitucional, como el Banco de la República, la Comisión Nacional del Servicio Civil o la extinta Comisión Nacional de Televisión, que no hacen parte de ninguna de las tres ramas del poder. Situación similar ocurre con las denominadas comisiones de regulación que, a pesar de ser ubicadas normalmente en la Rama Ejecutiva, son consideradas paradigmas de la tridivisión de poderes porque tienen características en su conformación, funciones y facultades similares a las de las denominadas autoridades administrativas independientes del derecho estadounidense.

Por último, al parecer continuando con la tendencia mencionada en el párrafo anterior, a partir del año 2011 se ha presentado un auge de entidades denominadas agencias estatales ${ }^{92}$, que "aparecen ajenas a las categorías de

91 Pueden consultarse en las siguientes normas: Decreto 3468 de 1982; Ley 30 de 1992; Ley 106 de 1993; Ley 302 de 1996; Decreto 1397 de 1996; Decreto 503 de 1997; Decreto 1320 de 1997; Decreto 1543 de 1997; Ley 434 de 1998; Decreto 368 de 1999; Decreto 797 de 1999; Decreto 982 de 1999; Decreto 2553 de 1999; Ley 590 de 2000; Decreto 1477 de 2000; Decreto 2762 de 2001; Decreto 955 de 2002; Decreto 1562 de 2002; Decreto 1782 de 2003; Decreto 3420 de 2004; Decreto 1098 de 2005; Decreto 3639 de 2005; Ley 1145 de 2007; Decreto 3110 de 2007; Decreto 2406 de 2007; Decreto 1015 de 2008; Decreto 1733 de 2009; Decreto 261 de 2010; Decreto 2374 de 2010; Decreto 4095 de 2010; Decreto 4702 de 2010; Resolución 2040 de 2010; Ley 1475 de 2011; Decreto 4362 de 2011; Ley 1530 de 2012; Ley 1564 de 2012; Decreto 1500 de 2012; Decreto 3011 de 2013; Decreto 20 de 2013; Decreto 1829 de 2013; Decreto 1591 de 2013; Decreto 2055 de 2014; Decreto 1776 de 2016.

92 No obstante, si se observa con detalle, "[h]ay que aclarar que unas se denominan 'agencias' pero en el fondo son unidades administrativas especiales (ver art. 5. ${ }^{\circ}$ de la Ley 1444 de 2011 y decretos 4152 y 4160 de 2011), sin embargo, otras sí tienen naturaleza jurídica 
órganos que en la práctica tradicionalmente han integrado nuestra administración pública"93 y que obedecen, según el ejecutivo, a "una reforma para [... acoplar el Estado a las necesidades de los tiempos actuales [... a las nuevas circunstancias, a los avances tecnológicos, a los nuevos problemas que surgen en las sociedades" ${ }^{\prime \prime 4}$.

De acuerdo con estas descripciones de la realidad, puede concluirse que la estrutura institucional y las funciones estatales ${ }^{95}$ no están configurándose atendiendo a una estricta separación entre órganos y funciones, sino que en el diseño de varias entidades estatales se está evitando su encaje en alguna de las tres gavetas de los clásicos poderes ejecutivo, legislativo y judicial. Ahora, con lo dicho no se pretende afirmar que ya no existan o vayan a desaparecer en el corto o mediano plazo las entidades típicas derivadas del principio de separación de poderes: de hecho, son también protagonistas en el mundo actual, simplemente se quiere destacar que estos antiguos diseños institucionales ahora conviven con nuevos diseños que se configuran con lógica diferente y que reflejan las condiciones sociales actuales.

\subsubsection{Carácter interno}

Antes de la expansión de la globalización, el derecho de cada Estado era principalmente interno; esta característica, por supuesto, también la tenía el derecho administrativo moderno, incluso de manera más marcada que otro tipo de disciplinas jurídicas. Sostiene Cassese que "[e]1 Derecho Administrativo tenía una fuerte conexión con el Estado, y éste con el territorio, entendido como espacio de identidad, por lo que se producía una influencia recíproca

de 'agencia' (ver decretos 4134, 4137 y 4165 de 2011); incluso la Autoridad Nacional de Televisión no se denomina 'agencia', si bien tiene naturaleza jurídica de tal (ver Ley 1507 de 2012)": RonAlD PACHECO, "La Autoridad Nacional de Televisión, zuna agencia estatal independiente?", Revista digital de Derecho Administrativo, n. ${ }^{\circ} 13$, Universidad Externado de Colombia, p. 64.

93 "A pesar de que en el artículo 211 de la Constitución y en el artículo 13 de la Ley 489 de 1998 se hace referencia a las 'agencias del Estado', la presencia de entidades con esta naturaleza solo se ha venido a desarrollar ampliamente por el legislador a partir del año 2011. Ahora, si se revisan los decretos 1050 y 3130 de 1968 y 130 de 1976, en ninguna de estas normas aparece una entidad con denominación de 'agencia"'. Nota 3.

94 Ronald Pacheco, "La Autoridad Nacional de Televisión, zuna agencia estatal independiente?", cit., p. 65, nota 5 .

95 "Por su parte, Willis Guerra Filho indica que en las sociedades hipercomplejas de la posmodernidad se mezclan creación (legislación) y aplicación (jurisdicción y administración) del derecho, tornando la linearidad del esquema de validación kelseniano por la referencia a la estructura jerárquicamente escalonada del ordenamiento jurídico en circularidad con el imbricamiento de las diversas jerarquías normativas, las tangled bierarchies de la teoría sistémica": Calixto Yonel, Enfoque sistémico en el derecho, Trabajo de investigación, Perú: Universidad Nacional Hermilio Valdizán, 2015, p. 474. 
entre fuerza y territorio" ${ }^{196}$. Se consideraba al derecho administrativo moderno como producto nacional e incluso reflejo de la cultura de la sociedad. ¿Qué más nacional que el derecho que regía -sobre todo en un comienzo- a la Rama Ejecutiva y-posteriormente-al ejercicio del poder del Estado o a la prestación de los servicios públicos por el mismo? Las respuestas a estas preguntas, hace unas décadas resaltaban el carácter esencialmente interno del derecho administrativo. Sin embargo, en la actualidad, incluso la propia pregunta generaría discusión. Desde luego que el derecho administrativo sigue siendo el régimen de la administración pública y de la función administrativa, pero ahora debe resolver problemas globales. En relación con lo primero, esto es, con el tema de la estructura administrativa, destaca Covilla que "organizaciones internacionales, a su vez, cuentan con una particular habilitación que el Estado les concede para que puedan adoptar decisiones sobre ámbitos que comúnmente son de su competencia" ${ }^{197}$. Frente a lo segundo, esto es, el ejercicio de función administrativa y especialmente su deber de protección a los ciudadanos, es el ámbito donde el derecho administrativo enfrenta sus mayores retos en la medida que debe responder a los fenómenos jurídicos, sociales y económicos que trae consigo el proceso de la globalización ${ }^{98}$. ¿Puede el derecho administrativo de hoy defender de la misma manera a los ciudadanos frente a la acción de un sujeto público o privado internacional? ¿Cómo un ciudadano puede ser protegido ante gigantes como Google o Twitter? ¿Cómo garantiza el derecho administrativo la libre y leal competencia entre agentes que tienen regímenes legales distintos, como por ejemplo, en el ámbito audiovisual con la irrupción de operadores over-the-top como Netflix ${ }^{99}$ o en el sector del transporte con la entrada de Uber? Estos son los principales problemas que debe afrontar el derecho administrativo y, por esa razón, cabe cuestionarse si un derecho clásico es adecuado para cumplir su función social en una sociedad posmoderna.

96 SABINO CASSESE, Derecho administrativo: bistoria y futuro, cit., p. 363.

97 Juan Carlos Covilla Martínez, "Identificación de la función administrativa", cit., p. 177.

98 Entendida por Boaventura de Sousa Santos como "el proceso a través del cual una determinada condición o entidad local amplía su ámbito a todo el globo y, al hacerlo, adquiere la capacidad de designar como locales las condiciones o entidades rivales": cit. por FRANCISCO BARBOSA, "El derecho y la historia: mirada convergente en la globalización", en GONZALO Ramírez (ed.), El derecho en el contexto de la globalización, Bogotá: Universidad Externado de Colombia, 2007, pp. 90 ss.

99 Para un estudio detallado de estos nuevos jugadores del mercado audiovisual, denominados over-the-top, ver Ronald PACHECO, Televisión y nuevas realidades tecnológicas y de mercado. Hacia el sistema de la comunicación audiovisual, tesis de maestría, Bogotá: Universidad Externado de Colombia, 2016, pp. 129 ss. 


\subsubsection{Fines de la actuación administrativa}

Es común en la doctrina decimonónica, fiel al principio de separación de poderes, encontrar posturas que entienen a la actividad administrativa -de forma similar a como se entiende la actividad judicial- como una mera ejecución de la ley ${ }^{100}$. Carré de Malberg expuso las distintas teorías que han estudiado la función administrativa, y dentro de estas describió cómo en unas se ha entendido que "el legislador es la cabeza que concibe y decide, mientras que la autoridad administrativa sólo es el brazo que ejecuta. Comprendida así, la administración no es únicamente una función subalterna subordinada a las leyes, sino que aparece como una tarea servil, como una actividad estrechamente encadenada, que no entraña ningún poder propio de iniciativa o apreciación, e incluso, a decir verdad, no consiste de ninguna manera en actos de voluntad"101. Sin embargo, estos fines de la actividad administrativa, entendidos como fines netamente ejecutivos o de mera conformidad con la legalidad, han adquirido otros ingredientes en los últimos años, sobre todo a partir de la introducción de principios constitucionales que orientan la acción administrativa ${ }^{102}$. De acuerdo con esto, la labor administrativa no es ya simplemente servil o encadenada a la ley -como se afirmó en algún momento-, sino que ahora tiene obligaciones concretas ${ }^{103}$. En este sentido, sostiene Barnes que "la acción de la Administración, los servicios que presta o que garantiza, han de ser eficaces, de calidad. Y a ello ha de contribuir el Derecho administrativo, que no puede contentarse con que aquella se ajuste en su actuación a la legalidad, en un reducido lenguaje o código 'binario' (legalidad-ilegalidad)"104. De lo expuesto se observa entonces una exigencia que, a pesar de que ya se comienza a sentir normal en los quehaceres administativos, es extraña a la dogmática inicial del

100 Juan Manuel Olarieta Alberdi, "La separación de poderes en el constitucionalismo burgués", Nómadas: Revista crítica de ciencias sociales y jurídicas, n. ${ }^{\circ} 32,2011$, pp. 344 ss.

101 R. Carré De MalberG, Teoría general del Estado, cit., p. 430.

102 Marín expresa esta idea señalando que "la racionalidad formal del Derecho ha propiciado la consolidación de una Administración burocrática que es racional en la medida que su actuar se verifica a través de la aplicación automática de premisas ya dadas, subsumiendo los hechos en la norma. No obstante, este modelo ha evidenciado una metamorfosis si se advierte que de la descrita Administración burocrática legal, se ha pasado al modelo, denominado por Clauss Offe, de la 'política administrativa del Estado social', en el que las normas se limitan a señalar objetivos, propósitos a alcanzar por una Administración que será la llamada a elegir los cauces de actuación jurídicos, personales y organizativos conducentes a su consecución": Hugo Alberto Marín Hernández, Discrecionalidad administrativa, Bogotá: Universidad Externado de Colombia, 2007, p. 144.

103 Un ejemplo concreto lo representa el artículo 209 de la Constitución Política colombiana, que destaca cómo debe ejercerse la función administrativa.

104 JaVIER BARNÉS, en la presentación a la obra de EBERHARD SCHMIDT-ASSMANn, Teoría general del derecho administrativo como sistema, Madrid: Marcial Pons, 2003, pp. XIX y XX. 
derecho administrativo decimonónico y es muestra de la complejidad social actual y de sus requerimientos.

\subsubsection{Unilateralidad de las decisiones administrativas}

Otra de las características clásicas del derecho administrativo moderno es la facultad reconocida a la administración pública para imponer 2 wsus decisiones de manera unilateral ${ }^{105}$. Afirma Ospina, en un estudio realizado en memoria del profesor Maurice Hauriou, que "[p]ara la realización de la función administrativa, la institución dispone de prerrogativas; poderes que le permiten actuar eficazmente sin la voluntad de los administrados e, incluso, contra su voluntad"106. No obstante, esta prerrogativa o carácter de unilateralidad de las decisiones de las autoridades administrativas, a pesar de continuar existiendo -como ocurre con la mayoría de las características esenciales del derecho administrativo-, ha comenzado, en los últimos años, a modularse, especialmente en campos altamente especializados como la genética, el medio ambiente, la economía, entre otros. En estos ámbitos, la acción de la administración no es por esencia impositiva, sino informada o conciliada con los sectores o destinatarios de su actividad. Vale la pena aclarar que la unilateralidad que se pretende destacar no es la posibilidad de tomar decisiones signadas o imputables exclusivamente a la autoridad administrativa, sino que el énfasis se hace, particularmente, en el proceso de formación de la decisión administrativa, independientemente de si la firma o no la administración. Se quiere resaltar que hoy en día, en palabras de Barnés, "ninguna administración es autárquica, ninguna administración lo sabe todo, ni la administración más competente profesionalmente del país más avanzado que podamos imaginar, lo sabe todo. ¿Acaso las crisis financieras o los mercados financieros se puede regular con la sabiduría y el poder de una única administración?"107. Un ejemplo que ilustra esta nueva necesidad de consulta o conciliación con los destinatarios de las decisiones administrativas lo representa el artículo 8, numeral 8 CPACA, en el que, a pesar de aclarar que en últimas la decisión la toma la administración, es necesario que los proyectos específicos de regulación y la información en que se fundamenten reciban opiniones, sugerencias o propuestas alternativas.

105 Santofimio se refiere a esta facultad como la autotutela de la administración pública. JaIME Orlando Santofimio Gamboa. Tratado de derecho Administrativo, cit., p. 36.

106 ANDRÉS OSPINA, "La decisión ejecutoria en la doctrina de Maurice Hauriou: la viga de amarre de un edificio varias veces remodelado", en Ensayos de derecho público. En memoria de Maurice Hauriou, Andry Matilla, Jaime O. Santofimio y Héctor Santaella Q. (coords.), Bogotá: Universidad Externado de Colombia, 2013, pp. 426 y 427.

107 JAVIER BARNÉS, "Transformaciones del derecho administrativo: historia y retos del derecho administrativo contemporáneo", conferencia en las IV Jornadas de Administración y Justicia, Buenos Aires. Disponible en: https://www.youtube.com/watch?v=Y2_UFdWDxqQ\&t=2432s [consultado en agosto de 2013]. 
En suma, algunas de las bases del derecho administrativo moderno, esto es, el principio de separación de poderes, el carácter interno o nacional de este derecho, la función de mera ejecución de la ley y la unilateralidad radical de sus decisiones, parecen no ajustarse ante las nuevas exigencias de la práctica, para la muestra, los ejemplos concretos en los que el derecho comienza a crear instituciones que parecen extrañas o "contrarias" a la Parte general del derecho administrativo. Por tal razón, habrá que mirar a la Parte especial, que es la frontera de esta disciplina con los demás sistemas con que interactúa, y ver cómo retroalimentar la Teoría general del derecho administrativo ${ }^{108}$. Dicha verificación excede el objeto de este escrito y lo único que este espacio permite es plantear los siguientes cuestionamientos:

- Teniendo en cuenta la rapidez con la que avanzan la economía, la tecnología, la ciencia, etc., y por consiguiente la necesidad de proteger a los ciudadanos ante esta situación, cpodría configurarse la legislación administrativa de manera flexible o principialística para permitir a las autoridades una reacción más eficiente?

- Partiendo de la eliminación de fronteras económicas y sociales y, por consiguiente, del crecimiento del poder de acción de grandes corporaciones mundiales, ¿debe el derecho administrativo ampliar sus fronteras y pensar en alianzas transnacionales?

- Si lo que sucede en la economía o la sociedad de otro país tiene consecuencias prácticas en nuestro sistema jurídico (p. ej., precios del petróleo, medio ambiente, redes sociales), ¿deben diseñarse nuestras políticas administrativas teniendo en cuenta esta interdependencia?

- Si la explotación de la economía tiende a sectores altamente especializados como el poder por los grandes datos (big data), la manipulación genética de organismos vivos, la energía nuclear, entre otros temas, ¿debería el derecho administrativo favorecer el contacto con la interdisciplinariedad?

- Algunos de los anteriores cuestionamientos han comenzado a tener manifestaciones en la práctica ${ }^{109}$, que se reflejan -como ya se dijo- en lo que podría denominarse la Parte especial del derecho administrativo: la creación de autoridades estatales ${ }^{110}$ con funciones y estructura no decimonónica que, más que pretender predecir con leyes intemporales cómo deben comportarse

108 Eberhard SChmidt-Assmann, La teoría general del derecho administrativo como sistema, cit., pp. $15 \mathrm{ss}$.

109 Así mismo, se observan integraciones regionales (p. ej., Unión Europea, Mercosur) que modifican la estructura y funciones administrativas de común acuerdo y se comienzan a adoptar normas técnicas con fuente no gubernamental.

110 Conocidas como agencias, que entraron en escena luego del "retiro por parte del Estado de grandes sectores de la actividad económica, sin que ello pudiera implicar un desentendimiento del desarrollo de dichas actividades. De esta manera, al liberalizar servicios, el Estado asumió un nuevo rol frente a las actividades en las cuales antes tenía un puesto principal, el de regulador": Julian Andrés Pimiento ECheVerRI, "La regulación. Análisis a partir de las 
ciertos sectores o mercados, establecen objetivos y una especie de marco de referencia con reglas de juego (parecen facultades normativas), con competencias administrativas que tienden a mantener la estabilidad de los sistemas regulando su funcionamiento $\mathrm{y}$, en ciertos casos, resolviendo conflictos de intereses (parecen facultades judiciales) ${ }^{111}$.

Como ya se expresó, con estas manifestaciones particulares, la tarea en este momento está en cabeza de la doctrina que debe realizar el ejercicio de ordenación entre la Parte general y la Parte especial del derecho administrativo. No se propone olvidar o cambiar radicalmente todos los avances en la materia. Desde luego que los actos administrativos que reglamentan la ley siguen existiendo, así como también los establecimientos públicos ${ }_{i}$ lo que se propone es reflexionar sobre la capacidad de ciertas figuras clásicas para resolver los problemas que se presentan en las sociedad actual. ¿Es posible que una autoridad solo con facultades de ejecución de la ley pueda resolver un problema de medio ambiente o del mercado de valores? A propósito de los problemas sociales, el científico Warren Weaver escribió un artículo ${ }^{112}$ en el que identificó los tipos de problemas a los que, en los últimos tres siglos, se ha enfrentado la ciencia, denominándolos problemas de simplicidad (siglo XVII), problemas de complejidad desorganizada (siglo Xx) y problemas de complejidad organizada (mediados del siglo XX) ${ }^{113}$. Este autor destacó cómo cada problema social requiere un tipo ideal de enfoque. A pesar de que pudiera pensarse que este tipo de referencias bibliográficas son extrañas al derecho y no aplican al mismo, Weaver describe el tercer tipo de problemas (complejidad organizada) con estas preguntas: ¿de qué depende el precio del trigo?, ¿cómo se puede estabilizar adecuadamente la moneda?, chasta qué punto es seguro depender de la libre interacción de fuerzas económicas como la oferta y la demanda?, ¿en qué medida deben emplearse sistemas de control económico para evitar

funciones jurisdiccionales de la Comisión de Regulación de Comunicaciones", Revista digital de Derecho Administrativo, n. ${ }^{\circ}$ 9, Universidad Externado de Colombia, 2009, p. 18.

111 Ver Pierre Bauby, Henri Coing y Alain de Toledo, en Aa.vv., Los servicios públicos en Europa P. I. Bernal (trad.), Bogotá: Universidad Externado de Colombia, 2010, p. 29.

112 Ver Warren Weaver, "Science and complexity", Rockefeller Foundation, New York City, 1948. Disponible en http://people.physics.anu.edu.au/ tas110/Teaching/Lectures/L1/ Material/WEAVER 1947.pdf

113 En el primer tipo de problemas, "una variable depende enteramente de la segunda y no de una gran cantidad de factores"; en el segundo, se trata de "problemas que contienen un número de variables muy grande con un comportamiento individualmente errático e, incluso, desconocido"; $\mathrm{y}$, en el tercer tipo de problemas, "[n]o son problemas simples sino propios de sistemas muy complejos, pero ante los cuales no caben técnicas o metodologías estadísticas o probabilísticas, ya que se dan procedimientos simultáneos de un gran número de variables y de factores interrelacionados en un todo orgánico": SERRANO-BOSQUET y CAPONI. "Warren Weaver y el Programa de Biología Experimental de la Fundación Rockefeller", cit. pp. $148 \mathrm{~s}$ 
que de la prosperidad se pase a la depresión? ${ }^{114}$. Frente a estas cuestiones surge otra pregunta: ¿será que el derecho -especialmente el administrativo- no tiene nada que ver con la complejidad organizada?

Para dar paso a la conclusión de este escrito, tal como se expuso en el capítulo segundo, es importante mirar la historia de la manera como se ha relacionado el derecho administrativo a lo largo de sus años de existencia con la cosmovisión de cada periodo histórico (pensamiento científico, forma de organización del poder, política pública o fines estatales, etc.); para ese propósito, de manera general, alguna muestra de estas relaciones históricas pueden resumirse en la siguiente gráfica:

\begin{tabular}{|c|c|c|c|c|}
\hline $\begin{array}{l}\text { Tesis explicativas del } \\
\text { objeto del derecho } \\
\text { administrativo }\end{array}$ & Sujeto & Objeto & $\begin{array}{l}\text { Sujeto- } \\
\text { objeto }\end{array}$ & ¿Interacciones? \\
\hline $\begin{array}{l}\text { Fases del derecho } \\
\text { administrativo }\end{array}$ & $\begin{array}{l}\text { Configuración } \\
\text { (construcción) }\end{array}$ & $\begin{array}{l}\text { Puesta en marcha } \\
\text { (acción) }\end{array}$ & $\begin{array}{l}\text { Evolución } \\
\text { (reacción) }\end{array}$ & $\begin{array}{l}\text { Re-configuración } \\
\text { (re-construcción) }\end{array}$ \\
\hline Pensamiento científico & Reduccionista & Reduccionista & Holista & Complejo \\
\hline Forma del poder estatal & $\begin{array}{l}\text { Separado en } \\
\text { órganos }\end{array}$ & $\begin{array}{l}\text { Separado en } \\
\text { órganos }\end{array}$ & $\begin{array}{l}\text { Crisis de la } \\
\text { separación }\end{array}$ & $\begin{array}{l}\text { Funcional en } \\
\text { autoridades }\end{array}$ \\
\hline $\begin{array}{l}\text { Política pública / fines } \\
\text { sociales }\end{array}$ & $\begin{array}{l}\text { Legalidad y } \\
\text { libertad }\end{array}$ & $\begin{array}{l}\text { Libertad } \\
\text { económica }\end{array}$ & $\begin{array}{l}\text { Intervención } \\
\text { económica }\end{array}$ & $\begin{array}{l}\text { Garantía de libertades } \\
\text { económicas y sociales }\end{array}$ \\
\hline Énfasis de la economía & $\begin{array}{l}\text { Ganadería, } \\
\text { agricultura }\end{array}$ & $\begin{array}{l}\text { Producción de } \\
\text { bienes }\end{array}$ & Servicios & Información \\
\hline $\begin{array}{l}\text { Ámbito de acción } \\
\text { de la economía }\end{array}$ & Nacional & Nacional & $\begin{array}{l}\text { Global } \\
\text { económica }\end{array}$ & $\begin{array}{l}\text { Global económica y } \\
\text { social }\end{array}$ \\
\hline Rasgos filosofía estatal & Estado de derecho & Estado liberal & $\begin{array}{l}\text { Estado social } \\
\text { de derecho }\end{array}$ & Estado regulador \\
\hline Énfasis actividad estatal & $\begin{array}{l}\text { Creación } \\
\text { estructura pública }\end{array}$ & $\begin{array}{l}\text { Policía } \\
\text { administrativa }\end{array}$ & $\begin{array}{l}\text { Servicios } \\
\text { públicos }\end{array}$ & $\begin{array}{l}\text { Conciliación de } \\
\text { intereses }\end{array}$ \\
\hline $\begin{array}{l}\text { Principal manifestación } \\
\text { administrativa }\end{array}$ & $\begin{array}{l}\text { Acto } \\
\text { administrativo } \\
\text { ejecutor de la ley }\end{array}$ & Reglamentos & Contratos & Regulación \\
\hline Estructura principal & $\begin{array}{l}\text { Establecimientos } \\
\text { públicos }\end{array}$ & $\begin{array}{l}\text { Establecimientos } \\
\text { públicos }\end{array}$ & $\begin{array}{l}\text { Empresas } \\
\text { estatales }\end{array}$ & $\begin{array}{l}\text { Autoridades } \\
\text { administrativas } \\
\text { independientes }\end{array}$ \\
\hline
\end{tabular}

Aun cuanto queda mucho por hacer en relación con el estudio del objeto del derecho administrativo, es posible acudir a la historia y al contexto en que cada institución jurídica surge y evoluciona para tener herramientas que permitan enfrentar la complejidad de la sociedad actual.

\section{CONSIDERACIONES FINALES}

En este escrito se intentó abordar el qué del objeto del derecho administrativo y el porqué del mismo. Es decir, se describieron las tesis que se crearon para

114 Warren Weaver, "Science and complexity", cit., p. 5. 
justificar el objeto del derecho administrativo y, posteriormente, se presentó una propuesta para explicar por qué estas tesis habían surgido como surgieron. El propósito de este último punto fue demostrar que una manera plausible de estudiar el objeto del derecho administrativo era recurrir a una perspectiva contextual y no exclusivamente disciplinar. Una vez identificadas estas dos posturas sobre el objeto del derecho administrativo es posible observar en la doctrina dos tendencias, una en la que la investigación se ha concentrado esencialmente en justificar una u otra postura o ambas al tiempo ${ }^{115}$, y otra en la que se considera que no es necesario dedicar esfuerzos a esta tarea debido a que, si después de tantos años no se ha podido encontrar el objeto del derecho administrativo, es porque seguramente no lo tiene. No obstante la necesidad e importancia de tales estudios, en este escrito se propuso acudir a un enfoque que tenga en cuenta no solo el objeto tradicional, sino también las relaciones del derecho administrativo con otras disciplinas para tratar de enriquecer la perspectiva del observador.

Pero además de esta perspectiva metodológica, ¿qué otro aporte se deriva de esta propuesta? En esencia, puede hablarse de un aporte ético-filosófico, que consiste en resaltar el carácter democrático y adaptativo del derecho administrativo porque siempre habrá espacio para el cambio y la evolución. El hecho de comprender que - por lo menos en este campo de estudio- no hay teorías verdaderas y/o falsas, sino teorías plausibles en determinado contexto, abre paso al desarrollo social y reduce el espacio a las posiciones desconectadas de la realidad. De esa manera el derecho administrativo no será "cerrado" frente a los avances sociales y podrá acudir a sus mecanismos de cambio (legislación, jurisprudencia) sin tener que estar atado a leyes "naturales" o eternas. Corroborar que el derecho administrativo no ha tenido un objeto de estudio inmutable permite concluir que su objeto de estudio es, precisamente, lo contrario, es decir, mutable ${ }^{116}$; por consiguiente, encontrar el objeto del derecho administrativo es encontrar sus conexiones con la cosmovisión de cada época.

115 Vale la pena ampliar esta idea con el siguiente texto de Kuhn: "Si se considerase como algo más que un acervo de anécdotas o como algo más que mera cronología, la historia podría provocar una transformación decisiva en la imagen de la ciencia que ahora nos domina. Dicha imagen ha sido extraída inicialmente, incluso por los propios científicos, sobre todo, del estudio de los logros científicos acabados tal como se registran en los clásicos y posteriormente en los libros de texto en los que cada nueva generación científica aprende la práctica de su oficio. Sin embargo, es inevitable que el objetivo de tales libros sea propagandístico y pedagógico, de manera que la idea de ciencia que de ellos se desprende no tiene más posibilidades de describir adecuadamente la empresa que los ha producido de lo que las tiene la imagen de la cultura nacional extraída de un folleto turístico o de un manual de idioma": THOMAS S. KuHN, La estructura de las revoluciones científicas, cit., p. 101.

116 En su momento, Forsthoff destacó que "[1]a multiplicidad en que se diversifican las distintas funciones de la Administración hace imposible toda fórmula unitaria. El Estado cuida, por medio de la policía, de la seguridad y el orden públicos; impone contribuciones y aplica los recursos obtenidos a su fin propio; construye carreteras y canales, regula su tráfico; 


\section{BIBLIOGRAFÍA}

Ariño O., Gaspar. Principios de derecho público económico. Modelo de Estado, gestión pública, regulación económica, Bogotá: Universidad Externado de Colombia, 2003.

Barbosa, Francisco. "El derecho y la historia: mirada convergente en la globalización", en Gonzalo Ramírez (ed.), El derecho en el contexto de la globalización, Bogotá: Universidad Externado de Colombia, 2007.

Bauby, Pierre, Coing, Henri y De Toledo, Alain, en aA.vv., Los servicios públicos en Europa, trad. P. I. Bernal, Bogotá: Universidad Externado de Colombia, 2010.

Bourdieu, Pierre y Teubner, Gunther. La fuerza del derecho, Carlos Morales de Setién Ravina (estudio preliminar y trad.), Bogotá: Siglo del Hombre Editores y Ediciones Uniandes, 2000.

Cabezas, N. y Mayorga, D. "La génesis del derecho administrativo: fenómeno y derecho de la administración romana", Revista digital de Derecho Administrativo, n. ${ }^{\circ} 16$, segundo semestre, Universidad Externado de Colombia, 2016.

CAPrA, Fritjof. La trama de la vida: una nueva perspectiva de los sistemas vivos, Barcelona: Anagrama, 2009

Castells, Manuel. La sociedad red, Madrid: Alianza Editorial, 1997.

Chevallier, Jacques. El Estado posmoderno, Bogotá: Universidad Externado de Colombia, 2011.

Covilla Martínez, Juan Carlos. "Identificación de la función administrativa internacional como criterio para definir la administración pública desde una perspectiva funcional", Revista digital de Derecho administrativo, n. ${ }^{\circ}$ 12, Universidad Externado de Colombia, 2014.

COOPer, Robert. "El Estado posmoderno", Revista Académica de Relaciones Internacionales, n. ${ }^{\circ} 1$, marzo, 2005.

Daros, W. R. "Crisis, licuefacción de los valores y fragilidad de las relaciones en la posmodernidad según Zygmunt Bauman", Estudios Filosóficos, LXIV, 2015.

distribuye, por medio de las oficinas de colocación, la mano de obra, y concede a ésta, por los seguros sociales, protección y atenciones; mantiene escuelas, universidades, museos y teatros; controla la energía, protege financieramente y bajo otros aspectos organizaciones y empresas de importancia; es titular de la moneda nacional a través Bancos propios, y en todas estas funciones ejercita el Estado actividad administrativa": ERNEST FORSTHOFF, Tratado de derecho administrativo, Madrid: Instituto de Estudios Políticos, 1958, p. 12. 
De Malberg, R. Carré. Teoría general del Estado, México: Fondo de Cultura Económica, 1998.

Duguit, León. Manual de derecho constitucional, Madrid: Librería Española y Extranjera, 1926.

Flórez Miguel, Cirilo. "René Descartes. La constitución de la Modernidad", en Biblioteca de grandes pensadores, Madrid: Gredos, 2011.

Flórez Ruiz, José Fernando. "De Maquiavelo al Estado postmoderno. Paradigmas políticos de aproximación al fenómeno estatal", Revista Derecho del Estado, n. ${ }^{\circ} 29$, julio-diciembre, 2012.

Forsthoff, ERnest. Tratado de derecho administrativo, Instituto de Estudios Políticos, Madrid, 1958.

Fouce, José Guillermo. "Frente a la posmodernidad", Fundamentos en bumanidades, Universidad Nacional de San Luis n. ${ }^{\circ}$ II, 1/2000.

Gershenson, Carlos. "Enfrentando a la complejidad: predecir vs. adaptar", Universidad Nacional Autónoma de México y Vrije Universiteit Brussel, mayo de 2009.

Koyré, Alexandre. Estudios de bistoria del pensamiento científico, Madrid: Siglo XXI Editores, 16. ${ }^{\text {a }}$ ed. en español, 2007.

Kunn, Thomas S. La estructura de las revoluciones científicas, Ensayo preliminar de Ian Hacking, Carlos Solís Santos (trad. e intr.); Denis Peña (trad. del ensayo), 4. . ed., México: Fondo de Cultura Económica, 2013.

Luhmann, NikLas. El derecho de la sociedad. México: Herder, 2009.

Luhmann, Niklas. Sociología política, Madrid: Trotta, 2014.

Malagón Pinzón, Miguel Alejandro. Vivir en policía: una contralectura de los orígenes del derecho administrativo en Colombia, Bogotá: Universidad Externado de Colombia, 2007.

Maldonado, Carlos E. Complejidad: ciencia, pensamiento y aplicación, Bogotá: Universidad Externado de Colombia, 2007.

Maldonado, Carlos E. "Política y sistemas nolineales: la biopolítica", en Dilemas de la política, B. Vela Orbegozo (coord.), Bogotá: Universidad Externado de Colombia, 2007.

Maldonado, C. E. "¿Qué son las ciencias de la complejidad? Filosofía de la ciencia de la complejidad", en C. E. Maldonado, "Derivas de complejidad. Fundamentos teóricos", Bogotá: UR, 2012. 
Maturana, Humberto y Varela, Francisco, El árbol del conocimiento, Buenos Aires: Lumen y Editorial Universitaria, 2013.

Mir Puigrelat, Oriol. "El concepto de derecho administrativo desde una perspectiva lingüística y constitucional", Revista de Administración Pública, n. ${ }^{\circ} 162$, septiembrediciembre, Madrid: Centro de Estudios Políticos y Constitucionales, 2003.

Najmanovich, Denise. Mirar con nuevos ojos nuevos paradigmas en la ciencia y pensamiento complejo, Biblos, 2008.

Marín Hernández, Hugo Alberto. Discrecionalidad administrativa, Bogotá: Universidad Externado de Colombia, 2007.

Mayer, Otto. Derecho administrativo alemán, t. I, Parte general, Buenos Aires: Depalma.

Montaña Plata, Alberto. La dimensión teórica de la jurisdicción contencioso administrativa, Bogotá: Universidad Externado de Colombia, 2005.

Montaña Plata, Alberto. Fundamentos de derecho administrativo, Bogotá: Universidad Externado de Colombia, 2010.

Olarieta Alberdi, Juan Manuel. "La separación de poderes en el constitucionalismo burgués", Nómadas: Revista Crítica de Ciencias Sociales y Jurídicas, n. ${ }^{\circ}$ 32, 2011.

Ospina Garzón, Andrés Fernando. "La decisión ejecutoria en la doctrina de Maurice Hauriou: la viga de amarre de un edificio varias veces remodelado", Ensayos de derecho público. En memoria de Maurice Hauriou, Andry Matilla, Jaime O. Santofimio y Héctor Santaella Q. (coords.), Bogotá: Universidad Externado de Colombia, 2013.

Ospina Garzón, Andrés Fernando y Montaña Plata, Alberto. "Separación de poderes y derecho administrativo: en la búsqueda de la partícula de Dios", $L a$ constitucionalización del derecho administrativo. XV Jornadas Internacionales de Derecho Administrativo, Bogotá: Universidad Externado de Colombia, 2014

PaCheCo, Ronald. "La Autoridad Nacional de Televisión, cuna agencia estatal independiente?", Revista digital de Derecho Administrativo, n. ${ }^{\circ} 13$, Bogotá: Universidad Externado de Colombia, 2015.

Pacheco, Ronald. Televisión y nuevas realidades tecnológicas y de mercado. Hacia el sistema de la comunicación audiovisual, tesis de maestría, Bogotá: Universidad Externado de Colombia, 2016.

Parejo A., Luciano. El concepto del derecho administrativo, Bogotá: Universidad Externado de Colombia, 2009 
Pimiento Echeverri, Julian Andrés. "La regulación. Análisis a partir de las funciones jurisdiccionales de la Comisión de Regulación de Comunicaciones", Revista digital de Derecho Administrativo, n. ${ }^{\circ}$ 9, primer semestre, 2009.

Pimiento, Julián. Derecho administrativo de bienes, Bogotá: Universidad Externado de Colombia, 2015.

Prigogine, Ilya. El fin de las certidumbres, Barcelona: Taurus, 1997.

Rodríguez Zoya, LeOnArdo G. y Aguirre, Julio LeÓnidas. "Teorías de la complejidad y ciencias sociales. Nuevas estrategias epistemológicas y metodológicas", Nómadas, Revista Crítica de Ciencias Sociales y Jurídicas, 30, 2011, 2.

Rocha Herrera, Leticia. "Descartes y el significado de la filosofía mecanicista", Revista Digital Universitaria, 10 de abril 2004, vol. 5, n. ${ }^{\circ} 3$.

Ross Ashby, W. Introducción a la cibernética, Buenos Aires: Nueva Visión, 1972.

Ruiz Rodríguez, Virgilio. "Santo Tomás de Aquino en la filosofía del derecho", Enclaves del Pensamiento, vol. X, n. ${ }^{\circ}$ 19, enero-junio, México: Instituto Tecnológico y de Estudios Superiores de Monterrey Campus Ciudad de México Distrito Federal, 2016, pp. 13-40.

Santofimio Gamboa, Jaime Orlando. Tratado de derecho administrativo, t. I, Bogotá: Universidad Externado de Colombia, 2007.

SCHMidT-AsSmAnN, EberhaRd. La teoría general del derecho administrativo como sistema, Madrid: Marcial Pons, 2003.

Serrano-Bosquet, Francisco Javier y Caponi, Gustavo. "Warren Weaver y el Programa de Biología Experimental de la Fundación Rockefeller", Sci. stud., vol. 12, n. ${ }^{\circ} 1,2014$, pp. 137-167. Disponible online [consultado el 26 de marzo de 2017].

Solozábal Echavarría, Juan José. "Sobre el principio de separación de poderes", Revista de Estudios Políticos, n. ${ }^{\circ}$ 24, 1981.

Teubner, Gunther. El derecho como sistema autopoietico de la sociedad global, Bogotá: Universidad Externado de Colombia, 2005.

Vargas-Hernández, José G. "Perspectivas de la posmodernidad institucional", Cuadernos de Filosofía Latinoamericana, vol. 32, n. ${ }^{\circ}$ 104, 2011.

Weaver, Warren. Science and complexity, New York: Rockefeller Foundation, 1948.

Yonel, Calixto. Enfoque sistémico en el derecho, Trabajo de investigación, Perú: Universidad Nacional Hermilio Valdizán, 2015. 
Consejo de Estado, Sección Tercera. Sentencia del 20 de agosto de 1998, rad. 14202.

Consejo de Estado, Sección Tercera. Sentencia del 21 de noviembre de 2013, rad. 46027.

Decreto 3468 de 1982.

Ley 30 de 1992.

Ley 106 de 1993.

Ley 302 de 1996.

Decreto 1397 de 1996.

Decreto 503 de 1997.

Decreto 1320 de 1997.

Decreto 1543 de 1997.

Ley 434 de 1998.

Decreto 368 de 1999.

Decreto 797 de 1999.

Decreto 982 de 1999.

Decreto 2553 de 1999.

Ley 590 de 2000.

Decreto 1477 de 2000.

Decreto 2762 de 2001.

Decreto 955 de 2002.

Decreto 1562 de 2002.

Decreto 1782 de 2003.

Decreto 3420 de 2004 .

Decreto 1098 de 2005.

Decreto 3639 de 2005. 
Ley 1145 de 2007.

Decreto 3110 de 2007.

Decreto 2406 de 2007.

Decreto 1015 de 2008.

Decreto 1733 de 2009.

Decreto 261 de 2010.

Decreto 2374 de 2010.

Decreto 4095 de 2010.

Decreto 4702 de 2010.

Resolución 2040 de 2010.

Ley 1475 de 2011.

Decreto 4362 de 2011.

Ley 1530 de 2012.

Ley 1564 de 2012.

Decreto 1500 de 2012.

Decreto 3011 de 2013.

Decreto 20 de 2013.

Decreto 1829 de 2013.

Decreto 1591 de 2013.

Decreto 2055 de 2014.

Decreto 1776 de 2016. 